Illinois State University

ISU ReD: Research and eData

Theses and Dissertations

3-25-2014

\title{
Causal Effects Of Language On Exchange Of Social Support In An Online Community
}

Sarah Anne Biehl

Illinois State University, sabiehl@ilstu.edu

Follow this and additional works at: https://ir.library.illinoisstate.edu/etd

Part of the Psychology Commons

\section{Recommended Citation}

Biehl, Sarah Anne, "Causal Effects Of Language On Exchange Of Social Support In An Online Community" (2014). Theses and Dissertations. 139.

https://ir.library.illinoisstate.edu/etd/139

This Thesis is brought to you for free and open access by ISU ReD: Research and eData. It has been accepted for inclusion in Theses and Dissertations by an authorized administrator of ISU ReD: Research and eData. For more information, please contact ISUReD@ilstu.edu. 


\title{
CAUSAL EFFECTS OF LANGUAGE ON THE EXCHANGE OF SOCIAL SUPPORT IN AN ONLINE COMMUNITY
}

\author{
Sarah A. Biehl \\ 86 Pages \\ May 2014 \\ This thesis reports the results of a research project that investigated the causal \\ effects of the frequency of affective processes on ratings of emotional distress of a \\ simulated online post. Second, this research investigated whether the levels of affective \\ processes within the simulated online post influence the levels of affective processes \\ within a natural support response. Lastly, the research explores the influence of positive- \\ emotion words and insight words within simulated supportive responses on ratings of \\ effective emotional support. \\ Four-hundred and forty-two undergraduate and graduate students were randomly \\ assigned to one of twelve experimental conditions. Simulated posts with low frequencies \\ of positive-emotion words and high frequencies of negative-emotion words were \\ associated with higher ratings of emotional distress and lower ratings of ability to cope.
}


When participants were asked to provide a supportive response, there was an interaction effect of positive-emotion words within the response for the post with a high level of positive-emotion words and low level of negative-emotion words. Lastly, in the third purpose, high levels of positive-emotion words within the supportive response were associated with higher ratings of the effectiveness, helpfulness in alleviating distress, and greater success in making the poster feel better.

These findings provide support for the influence of emotion on the perception of coping resources, as well support for online experimental research of affective processes. These findings suggest that individuals are likely to reinforce positive disclosure on the Internet with high levels of positive-emotion words. Lastly, positive-emotion words are associated with effective support, suggesting that these words may be seen as promoting resiliency and coping resources. 
CAUSAL EFFECTS OF LANGUAGE ON THE EXCHANGE OF SOCIAL SUPPORT IN AN ONLINE COMMUNITY

SARAH A. BIEHL

A Thesis Submitted in Partial Fulfillment of the Requirements for the Degree of

MASTER OF SCIENCE

Department of Psychology

ILLINOIS STATE UNIVERSITY

2014 
Copyright 2014 Sarah A. Biehl 
CAUSAL EFFECTS OF THE LANGUAGE ON EXCHANGE OF SOCIAL SUPPORT IN AN ONLINE COMMUNITY

SARAH A. BIEHL

COMMITTEE MEMBERS:

Jeffrey H. Kahn, Chair

J. Cooper Cutting 


\section{ACKNOWLEDGEMENTS}

I would like to thank my committee, Drs. Jeffrey Kahn, Cooper Cutting, and Gregory Braswell, who provided direction, feedback, and support during the development of this thesis. I would like to especially thank Dr. Jeffrey Kahn for his investment in my growth as a researcher and writer. I appreciate his professional guidance and support during this process.

S.A.B. 


\section{CONTENTS}

Page

ACKNOWLEDGMENTS $\quad$ i

$\begin{array}{ll}\text { CONTENTS } & \text { ii }\end{array}$

TABLES $\quad$ V

FIGURES

CHAPTER

I. THE PROBLEM AND ITS BACKGROUND 1

II. REVIEW OF RELATED LITERATURE 5

General Literature Review 5

Online Communities $\quad 5$

An Example Online Community: Reddit 8

Expressive Writing 11

The importance of emotional expression $\quad 14$

The importance of cognitive processing 15

Linguistic Inquiry and Word Count (LIWC) 16

Affective processes $\quad 19$

Cognitive processes $\quad 20$

Correlational Studies of Language in Online Support 21

Purpose of Proposed Study 24

Purpose 1: what words in a post lead people to respond to that post. 24

Purpose 2: what words do people naturally use
when responding to a post.

Purpose 3: what words in a response lead a response to be judged as helpful. $\quad 27$ 
III. METHODOLOGY 29

Participants $\quad 29$

Research Design $\quad 30$

Independent-Variable Stimulus Materials 33

Simulated Post 33

Simulated Response $\quad 34$

Dependent-Variable Measures $\quad 34$

Purpose 1: Perception of Distress 35

Purpose 2: Linguistic Inquiry and Word Count (LIWC) 35

Purpose 3: Perception of Effective Support 36

$\begin{array}{ll}\text { Procedure } & 36\end{array}$

IV. ANALSYSIS OF THE DATA 40

Content of Simulated Post and Participant

Perceptions of the Poster 40

Content of Simulated Post and Participant-
Generated Responses

Content of Simulated Response and Participant

V. SUMMARY, CONCLUSIONS, AND RECOMMENDATIONS 51

Content of Simulated Post and Participant Perception of the Poster 52

Content of Simulated Post and Participant-
Generated Responses

Content of Simulated Response and Participant
Perceptions of the Response

Limitations of Study $\quad 58$

Suggestions for Future Research $\quad 60$

$\begin{array}{ll}\text { Strengths of Study } & 61\end{array}$

$\begin{array}{ll}\text { Implications } & 62\end{array}$

$\begin{array}{ll}\text { REFERENCES } & 63\end{array}$

APPENDIX A: Solicitation Email $\quad 69$

$\begin{array}{ll}\text { APPENDIX B: Stimulus Materials } & 71\end{array}$

$\begin{array}{ll}\text { APPENDIX C: Initial Questionnaire } & 78\end{array}$ 


\section{TABLES}

Table $\quad$ Page

1. Descriptive Statistics of Frequency of Positive-Emotion Words and Negative-Emotion Words of Emotional Post on Outcome Variables

2. Descriptive Statistics of Levels of Positive-Emotion Words and Negative-Emotion Words of Post on Level of Positive-Emotion Words and Negative-Emotion Words of Response

3. Descriptive Statistics of Frequency of Positive-Emotion Words and Insight Words of Supportive Responses on Outcome Variables 


\section{FIGURES}

Figure

Page

1. Flow of participants in the study. 


\section{CHAPTER I}

\section{THE PROBLEM AND ITS BACKGROUND}

Online communities function as a social support system for some individuals. Two-thirds of adults use one or more online networks (Skelton, 2012), and many of these individuals use the Internet to receive anonymous emotional support. Within the next decade, researchers expect mental health services to be provided online with few exceptions (Abbott, Klein, \& Ciechomski, 2008).

Online support is an important issue in mental health because 1 in 5 young people suffer from mental health issues, yet only $30 \%$ receive professional help due to numerous barriers (Webb, Burns, \& Collin, 2008). Suicide hotlines are understaffed, so more people turn to online support for their emotional needs (Singel, 2012). The Internet is a medium that connects individuals with emotional support. A study of depression disclosure on Facebook indicated that almost $25 \%$ of college students display comments that meet criteria as symptoms of depression (Moreno et al., 2011). Positive responses provided from online communities have been associated with an increase in self-esteem and sense of well-being of older adolescents.

Despite the potential for help, there are many concerns associated with online social support. First, individuals may not receive a reply from the online community. For instance, in a longitudinal sample of 6,172 messages of the online community, Usenet, $27 \%$ of posts contained no response (Arguello et al., 2006). As a result, an individual 
may be propelled into further emotional distress. Second, a lack of online regulation may result in a negative response. In cases of low to medium levels of moderation (i.e., administrative oversight of web content) research has shown an increased level of "selfharm, depressive symptoms, contagion and normalizing self-harming behavior" (Webb et al., 2008, p.109). Therefore, a lack of response or a negative response may have a harmful effect on the individual.

In addition to situations with a lack of response or a negative response, the response may be invalidating, which may cause harm for the individual. Invalidation occurs when an individual denies a person's emotions (Kool, van Middendorp, Boeije, \& Geenen, 2009). People experience invalidation in some of the following ways: misunderstanding, non-acceptance, rejection, stigmatization, and suspicion. Receiving a response that mismatches the content of the post may have a harmful effect on the poster. In some cases, online users have committed suicide in response to negative feedback (Olanoff, 2012). Since online support lacks ethical principles, there is no standard reappraisal for situations where the individual is not receiving beneficial support. Therefore, this research is intended to understand how language usage impacts an individual's perception of posts and responses.

The literature on language usage of online communities demonstrates that language influences the response rate from the online audience (Arguello et al., 2006). Researchers found that online posts that contained a higher number of words reflecting cognitive mechanisms (e.g., cause, consider, think, know, maybe, always) received the highest number of replies in comparison to posts with words reflecting other psychological processes, like positive-emotion words (e.g., awesome, care, thank, 
easiness, yay, lucky) and negative-emotion words (e.g., emotional, whining, loser, mad, worthless, dumb). Overall, online postings with a higher frequency of words denoting cognitive mechanisms, positive emotions, and negative emotions received more replies from the community compared to posts that did not include these language types. In addition, Pennebaker (2011) found that increases in insight words (e.g., accept, become, know, means, understand, prove, and solve) and causal words (e.g., make, solve, outcome, thus, why, use, since) over time were associated with an improvement in health over 4 days of expressive writing. He hypothesized that using more insight and causal words may give the narrative account more coherence, indicating a level of emotional processing that is necessary in constructing a story about trauma.

Arguello et al. (2006) studied the natural effects of language usage on response rate; however, the field of psychology lacks experimental research on the association between language usage in a post and raters' perception of the necessity of a response. This study sought to fill a void in the literature by manipulating the emotional content of posts to understand the relationship of language and perception of emotional distress. By isolating the exchange of social support in online posts, I was able to investigate the causal effects of emotion words on the perception of need for support. Thus, the first purpose of this study was to understand whether certain language usage (specifically, the use of emotion words) elicited the belief that an online post requesting help deserved a supportive response.

Online responses are provided by individuals who lack formal training (Singal, 2010). While online users may have the best intentions in their responses, they may lack the qualifications to help the individual to get help. Suicide prevention hotlines train 
volunteers to console the caller by providing empathy instead of trying to solve the caller's emotional, sexual, or financial problems which may prove to be unsolvable. Yet, online users may respond to emotional posts with advice on the situation that posters may find unhelpful. Thus, the second purpose of this study was to observe how individuals naturally respond to an emotional post when asked to help the person feel better. Specifically, I explored what type of language is used in response to posts that vary in the expression of positive and negative emotion.

The third purpose was to examine the causal effects of insight words and positiveemotion words on the perception of helpfulness in an online, supportive response. In other words, responses that contain a high amount of insight words and positive-emotion words may be perceived as more helpful than responses with a low amount of insight words and positive-emotion words. Understanding how the language of support impacts the perception of the response will advance knowledge of what composites a helpful response to a request for online social support. Specifically, it is important to differentiate language that is helpful to someone in distress from language that is hurtful in responses. This insight will be helpful to understand the role of language in the perception of helpful, emotional support.

Therefore, in this study I investigated the impact of language on online support. Understanding how individuals react to posts and responses that vary in language content provided insight into what categories of words are beneficial in eliciting support and providing support. Then, researchers in the field of psychology can understand how language affects the process of soliciting and receiving help in online communities. 


\section{CHAPTER II}

\section{REVIEW OF RELATED LITERATURE}

\section{Online Communities}

\section{General Literature Review}

An online community is a virtual gathering place for individuals with a similar purpose and whose interactions are governed by norms and policies (Preece, 2000). An online community is defined as a group of individuals who exchange content (Arguello et al., 2008). Online conversations are concise and clear. Online communication occurs when an individual initiates conversation on a subject to audience members. The conversation is traditionally between limited audience members. These interactions are commonly referred to as computer-mediated communication (CMC). CMC is defined as human communication achieved through the use of computers (Herring, 1996).

Through CMC, individuals are able to come together and get their diverse needs met. Information exchange (50\%), friendship (24\%), and social support (11\%) were the most common answers for why individuals join online communities (Ridings \& Gefen, 2006). Online communities promote group interaction, which is helpful for individuals who are socially isolated (Rainee et al., 2011). In a recent survey, 75\% of Americans reported that the Internet has had a major effect on their capability to communicate with other Internet members. Group communication is maintained through the expectation that committed online visitors will respond (Arguello et al., 2006). 
There are demographic differences related to individuals who use the Internet for social relationships. In a 2012 survey, young adults were more likely to use popular social media sites than any other age group (Duggan \& Brenner, 2012). The age group 18-29 was most likely (83\%) to use a social networking site (e.g., Facebook, Twitter, Pinterest, Instagram, and Tumblr). In addition, women were more likely to be users compared to men, and people living in urban settings are more likely to use social networking sites than rural Internet users. It is interesting to note that these demographics are atypical for the website, Reddit. Reddit users are predominately male (Duggan \& Smith, 2013). In fact, men are twice as likely as women to be Reddit users. In addition, people under the age of 50 were more likely to use Reddit than those 50 or older. Specifically, individuals aged 18 to 29 were most represented for Internet users that visit Reddit (11\%). Overall, it is evident that young adults are the main demographic of online social websites.

Online communities are associated with positive benefits for individuals seeking social support, such as ovarian cancer patients (Gill \& Whisnant, 2012), individuals struggling with weight loss (Hwang et al., 2010), and individuals diagnosed with schizophrenia (Haker, Lauber, \& Rössler, 2005). Facebook users, in comparison to nonInternet users, reported a higher amount of social support, a stronger belief that most people can be trusted, and a greater number of close relationships (Hampton, Goulet, Rainie, \& Purcell, 2011). These positive interactions and perceptions reported by Internet users may influence people to expect positive interactions with other online users. Online communities also have the potential for negative interactions. Websites targeted towards individuals who engage in non-suicidal self-injury (NSSI) behavior have been associated 
with web content that reinforces, justifies, and glamourizes NSSI behaviors (Lewis, Heath, Michal, \& Duggan, 2012). Websites that lack recovery language are associated with high rates of ongoing NSSI behaviors. Fox, Ward, and O'Rourke (2005) studied the discourse of an online pro-anorexia website that promoted an anti-recovery model. In an experimental study, participants who were exposed to a pro-anorexia website compared to a website with average-sized models reported greater negative affect, lower selfesteem, and lower appearance self-efficacy (Bardone-Cone \& Cass, 2007). Therefore, the content of online support groups can have harmful effects on users.

Another negative interaction may occur when an individual receives no response called a "frozen thread" (Smithson et al., 2011). This problem is often due to mismatched expectations between the poster and audience or a lack of a clear way to respond to the post. Advice-giving responses are often rejected by poster. It is likely that individuals who seek support and either receive advice or get ignored will have unmet needs. Individuals who write advice-giving responses in reply to a suicidal post may send the message that the problem has an easy solution and can be invalidating to the suicidal identity of poster (Horne \& Wiggins, 2009).

It is important to note that the Internet has a faction of individuals who engage in negatives behaviors, such as trolling (About reddit, 2012). Trolling is a general term to describe any one of the following behaviors: aggression, deception, disruption, and success (Hardaker, 2010). Success refers to a situation when individuals reinforce trolling behaviors by giving the individual attention for negative behavior. An example of trolling is seen in a comment in response to a suicide comment on a sub-section of Reddit called Suicidewatch. In response to a post from a teenager who felt ignored by his parents, an 
individual commented, "To be honest, your mom is probably tired of you being a drama lama. Either shit or get off the pot. Stop crying wolf. Ether put that shotgun in your mouth and pull the trigger or shut the fuck up" (Kazan, 2010, p.1). Without follow-up it is impossible to predict what effect this response had on the suicidal individual. However, there have been cases where trolling responses on Reddit have resulted in suicides (Ries, 2010). In 2010, Bob Duncan wrote an ambivalent suicidal post that asked the online community for reasons why he should live. Some responses encouraged Duncan to kill himself. Five days later, Duncan's mother informed the Reddit community that Duncan had committed suicide. Therefore, online communities function as an exchange of social support; however, there are many risks associated with a self-governing website.

\section{An Example Online Community: Reddit}

Reddit is one popular example of an online community (Brown, 2012). The word Reddit is both a noun and a verb. As a noun, Reddit is defined as a "type of online community where users vote on content" (About reddit, 2012). As a verb, Reddit means "to take part in a Reddit community." Reddit is self-governing, and users are responsible for the content on the website (Brown, 2012).

Individuals who are involved in CMC on Reddit are called redditors (About reddit, 2012). Redditors are responsible for adhering to Reddit policies, called redditquette. Moderators are individuals who oversee redditors. Moderators are responsible for upholding redditquette and have the power to delete content that is objectionable or off topic. This process of CMC demonstrates that Reddit has forms of regulation to govern the online community. 
Self-regulation of content is also achieved through a token economy, where redditors build up karma. Users have the ability to upvote and downvote web content. An upvote signals that the user likes the content. As a result, the content moves up one in popularity relative to other postings.

Reddit has designed sub-sections, called subreddits, for individuals seeking social support, like makemefeelbetter (MMFB) (zjbird, personal communication, 2013). MMFB is an online community for individuals seeking social support. In total, 10,784 redditors belong to the sub-community. Online users are prompted to self-disclose with a message of the purpose of MMFB, “... many people have some great stories to tell about some not-so-great occurrences in their lives. This is a place to talk about it. Don't go through it alone! Talk amongst fellow Redditors who would be happy to help.” Redditors seeking emotional support write a post about their problem and end the post with a request for help.

For example, a post entitled, "Girlfriend problem," received 4 up-votes for the following post:

My girlfriend broke up with me. I know its something that happens but im depressed now. This is different. When I was with her she would laugh, smile, kiss me with passion, joke around, and everything that inquires a healthy relationship. But she just told me she wasn't happy that she wanted to break up because of it. She told me that she hasn't been happy for years and it has to be this way. But I don't understand because when were together we were happy. How can it be depression when she never complained or moped around at all. She was genuinely happy. Reddit... help me understand... help me stop crying... I feel 
helpfulness... alone ... abandoned... and I need a shoulder to cry on (personal communication, January 30, 2013).

In response, redditors submit comments, or responses, to the post to offer support in hopes of making the individual feel better. Here, the respondent received the highest response at 4 upvotes for the comment:

"As much as it will probably hurt for you to hear this, sometimes people just aren't happy. Even if they seem it, it's far easier to put on a happy mask and pretend that nothing's amiss than deal with the issues surrounding unhappiness. I'm not at all experienced with depression, but I do know that it makes you think in funny ways, which seems irrational but make sense to a sick mind. Check $/ \mathrm{r} /$ depression if you haven't, and see if that'll help shed some light on the situation. Being broken up with always sucks, and there's nothing I can do to change that. It's even worse when you end up questioning the person you spent time with's happiness. Let the tears come, they're part of the healing process. As time passes the pain will full and the good times you had together will come into focus. You're going to be ok. Humans are damned resilient, and I'm sure you'll come out of this a wiser (if sadder) person" (personal communication, January 31, 2013).

About 12 hours later the original poster responded with the comment "Thanks man. that makes me feel a little better. It will suck for a while but im sure it'll get better (personal communication, January 31, 2013). 


\section{Expressive Writing}

The above example of post and response is standard communication in online communities. The self-disclosure illustrated in the support-seeking post is similar to expressive writing. The online sub-community, makemefeelbetter, prompts members to freely write about their troubles. In a similar respect, the writing paradigm used in expressive-writing studies elicits members to disclose freely about negative experiences. Therefore, research on expressive writing was used as a framework in studying the benefits in receiving and providing emotional support in an online community.

Expressive writing has been studied using Pennebaker and Beall's (1986) writing paradigm. In the writing paradigm, individuals are prompted to write their deepest feelings in response to a stressful or traumatic event. Expressive writing became a field of research after Pennebaker and Beall implemented a writing paradigm method to understand the effect of traumatic experiences on physical health. This initial expressivewriting study created the basic writing paradigm that has been replicated in many studies on disclosure (Pennebaker, Mayne, \& Francis, 1997). The basic writing paradigm is structured so that participants write in small sessions lasting 15-20 minutes over the span of 3-5 days. The basic writing paradigm is often studied with an experimental design, in which participants are randomly assigned to one of two or more groups. Participants in control conditions are prompted to write about superficial topics, whereas participants in experimental conditions are instructed to write about a traumatic experience. While the traditional writing paradigm is composed of sessions throughout the course of 3 days, Greenberg, Wortman, and Stone (1996) found that expressive writing can produce positive effects even after a single writing time. 
Expressive writing has been primarily studied using the writing paradigm (Pennebaker, 2011). The writing paradigm is mostly confidential, in that the individual is not responsible for sharing his or her self-disclosure with anyone but the researcher (Pennebaker et al., 1997). There is a lack of research on the influence of feedback on expressive writing. Therefore, little is known about the causal effects of an online audience on expressive writing. Later, I will discuss the naturalistic research that studies the feedback component of social support. Still, the findings of expressive writing studies served as a foundation for understanding how language influences psychological and physical outcomes.

Expressive writing has been shown to have positive physiological benefits. Pennebaker and Beall (1986) found that expressive writing was associated with improvements in long-term physical health, such as a reduction in the number of illnessrelated visits to the doctor. Disclosing about traumatic events has been associated with changes in health, particularly a change in "people's thinking patterns, emotional responses, brain activity, sleep and health behaviors, and so forth" (Pennebaker, 2011, p. 5). In two meta-analyses on expressive writing, expressive writing was associated with positive long-term outcomes, specifically improvements in reported health, physiological functioning, specific disease outcomes, illness behaviors, healthy dieting, and general functioning (Frattaroli, 2006; Smyth, 1998). Smyth, Stone, Hurewitz, and Kaell (1999) found that expressive writing improved respiratory functioning in asthmatic patients. Pennebaker, Kiecolt-Glaser, and Glaser (1988) found that expressive writing improved immune functioning. Stanton, Collins, Rodiguez-Hanley, and Austenfeld (2002) found that expressive writing with breast cancer patients was associated with reductions in 
medication visits for cancer-related morbidities. Inhibiting emotions related to traumatic events has been associated with negative health symptoms, such as increased anger, arousal, and blood pressure (Lepore, 1997). Lepore and Smyth (2002) argue that when individuals repress emotions regarding stressful events the effort to repress memories causes additional stress on the body.

Expressive writing is associated with improvements in psychological variables (Lepore, 1997). Expressive writing has been associated with a reduction in intrusive thoughts related to a stressful event. Frattaroli (2006) found that expressive writing had an effect on participants' level of distress, depression, and positive functioning. College students in an expressive writing group reported reductions in reports of depressive symptoms compared to those of the control group (Smyth, 1998). Expressive writing has helped individuals cope with recent unemployment (Spera, Buhrfeind, \& Pennebaker, 1994). At the end of the study, participants reported a more positive attitude about their old jobs and finding new employment than their initial report. It is evident that researchers have shown that expressive writing has benefits on psychological variables.

The previous studies examined expressive writing without attention to online experiences. Expressive writing, written in the form of an online blog, has been associated with improvement on emotional, social, and self-esteem measures (BonielNissim \& Barack, 2011). Researchers randomly assigned participants to either blog with responses disabled or responses available. Individuals who blogged about emotional difficulties and received responses reported less emotional and social distress than those who blogged without responses. In summary, expressive writing is a robust procedure 
shown to be an effective coping mechanism for negative experiences (Smyth \& Pennebaker, 2008).

The importance of emotional expression. Pennebaker, Colder, and Sharp (1990) argued that individuals cope with traumatic experiences through predictable steps to process this information surrounding the event, called the Inhibition-Confrontation Approach. The coping process in dealing with trauma is made up of two components, emotional expression and cognitive processing (Ullrich \& Lutegendorf, 2002).

Emotional expression is defined as an active, purposeful effort to express one's emotions through intrapersonal (e.g., expressive writing) and interpersonal means (Stanton, Kirk, Cameron, \& Danoff-Burg, 2000). Pennebaker and Beall (1986) theorized that emotional expression involves exposure to repressed traumas that have had a stressful impact on physical and psychological functioning.

Compared to an emotional expression, emotional inhibition is defined as a tendency to withhold or not disclose significant experiences to others (Lepore, 1997). In situations of emotional inhibition, individuals suppress their emotions and feelings related to a stressful stimulus, resulting in avoidance of the stressful event. The stigma surrounding trauma causes many people not to talk about the events due to social consequences of embarrassment, disapproval, or punishment (Pennebaker, 1989).

Repression of emotions has been associated with negative health (Pennebaker et al., 1990), whereas emotional expression has been associated with positive benefits. Breast cancer patients who were high in emotional expression reported fewer doctors' visits, improved physical health and vigor, and decreased distress 3 months later compared to breast cancer patients who were low in emotional expression (Stanton et al., 
2000). Lepore and Ragan (2000) found that talking and validation of feelings after exposure to a stressor was associated with fewer intrusive thoughts that individuals that did not talk after exposure. Thus, expressing emotions is a component of the coping strategy for stressful events.

Pennebaker (2004) theorized that emotional expression improves coping due to processes of emotional adaptation, similar to habituation. A stressful stimulus, such as an intrusive thought, typically results in a negative emotional response (Lepore, 1997). Habituation is defined as repeated exposure to a stressful stimulus that results in an adaptive emotional response. This exposure to emotions is the first part of the process in coping. Once the individual is aware of the emotion, it is important to consider how the individual makes sense of the event. It is through this process of emotional expression that emotions and feelings regarding a stressful stimulus surface and cause the individual to contemplate and evaluate the situation.

The importance of cognitive processing. Pennebaker (1989) suggested that emotional expression requires the individual to confront the stressful event through contemplating and evaluating stressor-related thoughts and feelings. This process is referred to as cognitive processing (Pennebaker, 2004). An adaptive change in the way an individual thinks about the situation will result in fewer intrusive thoughts. The coping process works by closing the gap between how the individual thinks about the stressor in an aversive way and how they think about it in an understanding, rational way (Lepore, 1997). Due to the unexpected nature of stressors and traumatic events, people are naturally inclined to attempt to understand traumatic events (Pennebaker et al., 1990). Writing about the emotionally charged event may be the first time that the individual has 
to explain the event that forces the individual to label, structure, and organize it (Pennebaker, 2004). Expressive writing accelerates the coping process by giving the individual an outlet to come to understand and organize the traumatic event (Pennebaker et al., 1990). Together, the emotional and cognitive components involved in the adjustment to trauma are called the Inhibition-Confrontation Approach (Ullrich \& Lutgendorf, 2002).

In summary, research has shown when and how expressive writing is effective in improving physical and mental health symptoms. The writing paradigm has been a key method for understanding how individuals cope with traumatic experiences. Understanding the coping process in response to stressful events is an important framework to use when selecting word categories that reflect these constructs.

\section{Linguistic Inquiry and Word Count (LIWC)}

To measure the impact of emotional expression and cognitive processing on the coping process it is necessary to count the frequencies of language that individuals use in expressive writing. I used a program to count the constructs of emotional expression and cognitive processing outlined in expressive writing. This program, called the Linguistic Inquiry and Word Count (LIWC), measured the frequencies of language usage to quantify emotional expression and cognitive processing in writing.

LIWC was developed as an effective and efficient way to analyze the frequencies of emotional, cognitive, and structural units of language that are present in written and verbal speech samples (Pennebaker, Chung, Ireland, Gonzales, \& Booth, 2007). The LIWC has two components, the text analysis file and the built-in dictionary. The text analysis file is a transcript. The program starts with the first word, also called the target 
word, of the transcript and codes the properties of that word. The target word is matched with built-in dictionary files that detect psychological constructs. The first application of the LIWC was developed to measure the psychological content of language efficiently (Tausczik \& Pennebaker, 2007) and, more specifically, to track emotional states through emotional components of language (Pennebaker, 2011).

Words for the dictionary of the LWIC were chosen based on gathering relevant literature and brain-storming amongst three to six judges (Pennebaker et al., 2007). These judges selected a list of words which were then rated by three independent judges. Based on the words amassed from the brainstorming stage, the judges were instructed to decide whether to add, keep, or discard a word from the dictionary. Two of three votes from the judges were needed for words to be added, kept, or discarded. Words that are selected for the dictionary file are referred to as dictionary words. Word categories are groups of dictionary words that fall under a particular domain. So, target words that match dictionary words are counted towards the word category. Structural components, like word count and sentence punctuation, are logged as the program processes target words. The program is designed to give output that lists the frequencies word categories to measure different components of content. These frequencies are represented as percentages.

The LWIC has two updated versions, LIWC2001 and LIWC2007, which expanded the dictionary and modernized the software program (Pennebaker et al., 2007). The third revision of the LIWC, LIWC2007, contains approximately 4,500 words and word stems. Word stems include modified versions of a word and are treated as the word itself. The LIWC was streamlined, and words that had very low rates of usage, poor 
reliability, or poor validity were taken out of the dictionary. In recent updates, judges reexamined the most used words in the dictionary and created new categories. They also added new words to the dictionary to create a broad and modernized dictionary.

The LWIC has 80 output variables that are summarized in a designated output file (Pennebaker et al., 2007). The most elementary word categories are the four general descriptor categories which include total word count, words per sentence, percentage of words captured by the dictionary, and percent of words longer than six letters. The remaining categories are standard linguistic dimensions, psychological constructs, personal concerns, and relativity. Categories are arranged hierarchically. Standard linguistic dimensions are composed of 22 subcategories, such as the percentage of words in the text that are pronouns, articles, and auxiliary verbs.

One subcategory of linguistic processes, function words, has been studied extensively (Chung \& Pennebaker, 2007). Function words are defined as words that glue together the content words of the sentence, like pronouns, articles, auxiliary verbs, ad prepositions, conjunctions (Pennebaker et al., 2007). Chung and Pennebaker (2007) examined the frequency of function words to study social and personality processes. A high frequency of first-person pronouns has been associated with depression (Rude, Gortner, \& Pennebaker, 2004). The next category, personal concerns includes seven categories (e.g., work, achievement, leisure, home, money, religion, and death) (Pennebaker et al., 2007). Lastly, relativity, or spoken categories, refers to words that fall under assents (e.g., agree, okay, yes), nonfluencies (e.g., er, hm, umm), and fillers (e.g., blah, Imean, youknow). While function words, personal concerns, and spoken categories 
are main categories of the LIWC, psychological processes best tap into measuring emotions and cognitions.

The LIWC category, psychological processes, is composed of the following subcategories: social processes, affective processes, cognitive processes, perceptual processes, and biological processes (Pennebaker et al., 2007). The two most relevant to expressive writing are affective and cognitive processes. I was interested in measuring the affective and cognitive components of the content of online posts and responses. These two subcategories represent words that tap into the construct.

Affective processes. Affective processes are comprised of positive-emotion words (e.g., love, nice, okay, LOL, sweet) and negative-emotion words (e.g., hurt, ugly, nasty, shit, jerk). Negative-emotion words are made up of three subcategories: anxiety, anger, and sadness.

Use of higher positive-emotion words compared to negative-emotion words has been related to better health (Pennebaker et al., 1997). Use of positive emotion words have been shown to be associated with longevity (Danner, Snowdon, \& Friesen, 2001). In a longitudinal study involving the autobiographies of nuns, researchers found a negative correlation between positive emotional content of writings and mortality. In addition, a high frequency of positive-emotion words in expressive writing on students' transition to college has been associated with improved physical health (Pennebaker \& Francis, 1996). Danner and colleagues (2001) suggested that emotions are a key component in coping with negative life events. Emotion-based constructs, such as optimism and positivity, may reflect a buffer to potential harmful effects of long-term negative emotion. 
Individuals who used more negative-emotion words when discussing traumatic events reported more negative feelings about self than individuals who used fewer negative-emotion words (Cardefia \& Spiegal, 1989). A positive relationship between a high usage of negative-emotion words when discussing a traumatic experience and negative self-concept may influence individuals to perceive posts as more in need of a response due to the increased in severity of the root of the problem.

Cognitive processes. Insight words fall under the larger category, cognitive processes, which is a subsection of psychological processes. Insight words (e.g., think, know, consider, realize, and understand) are a function of self-reflective thinking. Insight words represent an individual's internal understanding of an event, like schema representations of how individuals believe the world should work. In other words, insight words reflect an individual who is attempting to understand or work through an event (Pennebaker \& Francis, 1996). Insight is a cognitive process that involves an effort to understand of how a stressful event aligns with an individual's beliefs about how the world should operate. A high usage of insight words reflects an individual's attempt to coincide external events with their schematic views. Pennebaker, Mayne, and Francis (1997) found that in six expressive writing studies, individuals who increased the frequency of insight words saw greater health improvements.

An increased usage of cognitive processes has been studied in expression writing, especially in relation to health improvements. A decrease in the expression of negative emotion over time has been linked to health benefits when paired with an increase in cognition words (Schwartz \& Drotar, 2004). An increase in the rate of cognitive words has been associated with an improvement in physical health but not mental health 
(Pennebaker et al., 1997). Participants who increased the use of cognitive words also reported a decrease in physical symptoms, an improvement in grades of those who were enrolled in college, and a short time to find employment of those who were unemployed. Pennebaker, Mayne, and Francis (1997) analyzed the writing of individuals whose partner recently died of AIDS. Participants who increased the rate of cognitive words over time were less prone to worry about death 1 year later. Cognitive processing is therefore a component of expressive writing that influences health benefits due to a sophisticated level of understanding of life events. Cognitive processing may be a form of resiliency that enables the individual face aversive life events towards greater understanding and insight in comparison to those are in denial about life circumstances.

\section{Correlational Studies of Language in Online Support}

Although there have been many experimental studies on emotion words and cognitive processes involved expressive writing, there is a lack of research on experimental studies that mimic online support. Nevertheless, it is important to understand the correlational relationship between language usage and online support to make predictions for this experimental study.

The language used in online support has been studied naturalistically. Kramer, Fussel, and Setlock (2004) researched the frequency of language in a bipolar chat room. Researchers examined chat messages generated by 267 chat-room visitors. Researchers found that online users commonly used the following LIWC categories: social processes, pronouns, cognitive processes, and affective processes. In addition, there was a positive correlation between the word, $I$, and negative-emotion words, as well as a positive correlation between the word, you, and positive-emotion words. Since support-seeking 
posts are written in first-person, this research suggests that support-seeking posts will have high amounts of negative-emotion words. On the contrary, support-providing responses are written in response to the poster, so the writer may use more you words as well as positive-emotion words.

Arguello et al. (2006) studied common elements of posts that were successful in receiving a response. Posts that contained high amounts of cognitive-processes words, positive-emotion words, and negative-emotion words received more responses than those that did not. Posts with positive-emotion words received slightly more responses than posts with negative-emotion words. However, this study was conducted on eight subforums, some of which had little to do with online support. Only two of the eight subforums (breast cancer and depression) were concerned with social support. The remaining six were on topics on personal interest, sports, and recreation. Unfortunately, researchers grouped all sub-forums together for their analysis. While researchers suggested that use of positive-emotion words led to more responses than negative-emotion words, this finding may not have the same application in online social support.

In an online community specific to social support, negative emotion words may foster a reaction from audience members. Surfacing of negative emotions may be more unpleasant for the poster to confront, especially if the individual has not coped with the stressful event. Negative emotion may have a different response rate in this study compared to research by Arguello and colleagues (2006) based on the nature of the purpose of the post. Individuals who seek and provide information may be more inclined to respond to positive-emotion words compared to individuals who are seeking and 
providing emotional support. My research studied the relationship between emotional language and number of replies in the context of online support communities.

The degree of perceived helpfulness of online communication has been studied by Barak and Bloch (2006) in an online support service for individuals in crisis. The website, SAHAR, is based in Israel, and trained staff members provide online support sessions. Researchers were interested in factors associated with helpfulness of online support. Helpfulness was assessed from the perspective of the client and the paraprofessional. In their first purpose, helpfulness, as measured by clients who voluntarily mentioned the session as helpful, was associated with conversations that had depth, smoothness, arousal, and positivity. Paraprofessional's reports of helpfulness were associated with longer texts of the client and helper as well as total text length. Barak and Bloch (2006) found no significant effect of positive-emotion words and negative-emotion words between the helpful responses and other responses.

The exchange of online support has primarily been studied naturalistically, making it difficult to understand the causal effects of words on social language (Arguello et al., 2006; Barak \& Bloch, 2006; Davison, Pennebaker, \& Dickerson, 2000; Home \& Wiggins, 2009; Mulveen \& Hepworth, 2006; Smithson et al., 2011). At best, this literature can provide information about the correlational relationship between language usage and online support behavior. Thus, the experimental effects of word usage and the perception of support seeking posts and supportive responses are unknown. The field of psychology has yet to understand the selection process of the individual in determining words that best convey feelings of distress and, in turn, the most effective words to convey support. Varying the frequency of language of specific psychological processes 
(i.e., positive-emotion words, negative-emotion words, and cognitive-process words) resulted in differences in the perception of support-seeking posts and the perception of degree of effective support-providing responses. As previously mentioned, there are many potential negative consequences that are involved in posting a support-seeking online post on the Internet. Therefore, it is reasonable to expect that individuals may package their posts and responses based on the influence of others.

\section{Purpose of Proposed Study}

I was interested in the frequency of words individuals use in the communication of emotional support and how these words impact the perception of needed support of members of an online community. Unlike past studies, I examined this issue experimentally. I manipulated the language used in posts requesting help as well as the

language used in responses. This methodology allowed me to determine how individuals seek and provide emotional support on an online community comprised of untrained volunteers.

Purpose 1: what words in a post lead people to respond to that post. First, I focused on the frequency of positive and negative emotional language of online posts. I investigated the causal effects of language usage of an emotion-seeking post on the perception of the necessity of supportive responses of audience members. The degree of emotional severity of the post as perceived by audience members has important implications for how emotional posts are ranked by online communities. The emotional composition of a post, judged by the frequency of positive-emotion words and negativeemotion words, has been suggested to impact the degree of perceived amount of help- 
needed. Language may play a factor in how individuals organize and present their emotions to others to best elicit a response (Kahn, Tobin, Massey, \& Anderson, 2007).

The literature (Pennebaker et al., 1997; Pennebaker \& Francis, 1996) suggests that a moderate amount of negative emotion words and a high number of positive emotion words are associated with improvement in health. Individuals who report positive emotions are perceived as having greater coping skills and resiliency, whereas individuals who focus on negative emotions are associated with tunnel vision of limited resources to alleviate the problem. (Fredickson, 1998). Extrapolating upon this reasoning, an online post that contains a high amount of negative-emotion words and a low amount of positive-emotion words may give the audience the perception that the poster has more distress and less ability to cope. I expected to find a main effect for positive-emotion words and a main effect for negative-emotion words. I did not expect to find an interaction effect. A high level of negative-emotion words was hypothesized to be independent of a low level of positive-emotion words to influence participants' perception of distress of the poster. I expected there to a main effect for positive-emotion words and negative-emotion words on the perception of distress.

\section{Purpose 2: what words do people naturally use when responding to a post.}

Second, I was interested in the linguistic composition of a supportive response to a support-seeking post. It is more beneficial to the field of psychology to study the language of untrained volunteers of online communities than trained volunteers or staff members since the former are not subject to ethical principles or administrative oversight. Participants were intended to simulate online community members. These naturalistic responses were coded by the LIWC to study frequency of affective processes. The second 
purpose of this study was to measure the frequencies of words that individuals use when writing a response to a simulated post asking for help. Participants were asked to respond to a help-seeking post with the goal of making the poster feel better. The response was transcribed and analyzed with the LIWC.

Next, I speculated that individuals would naturally provide empathetic responses that validate the emotions of the poster, as is common with trained helpers (Ivey \& Ivey, 2008). Introductory counseling techniques involve accurate empathy, a skill that involves identifying and repackaging the emotion. Even individuals with minimal training in psychology may be inclined to validate the emotional experience of the poster.

Supportive responses that reply to support-seeking posts with high positiveemotion words and high negative-emotion words were expected to mirror the frequencies in the original post. I hypothesized that a participant who receives a post that is high in positive-emotion words and high in negative-emotion words will respond with a supportive post that is high in positive-emotion words and high in negative-emotion words. The manipulated variable was the level of positive-emotion words and negativeemotion words. The independent variable was the participant's assignment to one of the four experimental conditions. In other words, the level of positive-emotions words and negative-emotion words of the first purpose was expected to carry over into the second purpose of this study. The dependent variable was the LIWC output of positive-emotion and negative-emotion words in the participant's response. I ran two different analyses since there are two dependent variables. I expected positive-emotion words in responses to match the level of positive-emotion words of the original post. Therefore, I expected there to be a main effect for positive-emotion words and no main effect for negative- 
emotion words. With respect to negative-emotion words in responses, I expected negative-emotion words of responses to match the level of negative-emotion words of the original post. Along this reasoning, I expected to find a main effect for negative-emotion words and no main effect for positive-emotion words.

\section{Purpose 3: what words in a response lead a response to be judged as helpful.}

The third purpose of this study was to examine the relationship between language usage of a supportive response and the perceived effectiveness of support in response to the original post. The literature on language involved in expressive writing suggests that the content of language in supportive responses occurs when there is a high amount of insight words (Pennebaker et al., 1997; Schwartz \& Drotar, 2004). Pennebaker et al. (1990) suggested that individuals accelerate the coping process when connections between external events and internal beliefs are made in an attempt to understand the event. Therefore, in this study I hypothesized that responses that encourage the poster to make connections between the stressful event and how the individual interprets the event will be perceived as more helpful than those that do not. Responses contained either high or low amounts of positive-emotion words and insight words in a 2-by-2 factorial design. Due to a technical error, there was one conditioning missing from the 2-by-2 factorial design. Participants who were intended to be assigned to the condition with low insight words and low positive-emotion words were actually assigned to the condition with high insight words and low positive-emotion words. Prior to this error, I hypothesized that responses that include more insight words would be rated as more helpful than responses with low insight words. I hypothesized that while both LIWC categories are important, both are not required for a participant to rate the post as effective. Rather, I expected that 
an effective supportive response needed at least one of the two variables. Therefore, I expected to find an interaction between positive-emotion words and insight words. Due to the missing condition, I was unable to test for interaction effects. I expected to find main effects for positive-emotion words and insight words, meaning that each variable would contribute to changes in the amount of perceived effectiveness. In my results, I specifically focus on my hypotheses for positive-emotion words on perception of effective support. Prior research on expressive writing has demonstrated that positiveemotion words are associated with improvements in physical health (Pennebaker et al., 1997; Pennebaker \& Francis, 1996). In addition, I speculated that supportive responses with high levels of optimism and positivity, reflected in positive-emotion words, may be perceived as helpful because they promote resiliency in the original poster (Danner et al. 2001). 


\section{CHAPTER III METHODOLOGY}

\section{Participants}

Participants were recruited by a solicitation email that was sent to undergraduate and graduate students enrolled at a large public university in the Midwest (Illinois State University). As an incentive, participants had the opportunity to win a $\$ 25$ gift certificate to Amazon upon the completion of the study. Students were required to be 18 years or older to participate in this study. I aimed to have a sample size of 400 participants. This number reflects the necessary sample size, 393 participants, for a small effect size, at an alpha level (a) of .05, when comparing individual mean differences (Cohen, 1992).

Four-hundred and forty-two participants participated in this study. The average age of participants was 22.61 years old $(S D=6.03)$. Nearly three-fourths $(73 \%)$ of the sample were women $(N=319)$. Of the remaining participants, 116 were men, and 1 identified as a transgender. Of the 437 who identified a sexual orientation, 410 were straight, 9 were gay, 3 were lesbian, and 15 were bisexual. In regards to ethnicity, 371 identified as Caucasian, 26 identified as Latino or Hispanic, 19 identified as AfricanAmerican, and 7 identified as "other, please specify" (e.g., African, East-Indian, Foreign student, Indian, Middle Eastern, Mixed, and Multi-ethnic). Of the 437 who identified their year in school, 123 were seniors, 100 were juniors, 95 were graduate students, 74 were freshmen, and 45 were sophomores. 
Of the 438 participants that chose to answer items on the demographic questionnaire, participants self-reported an average score of $3.94(S D=0.77)$ for average level of empathy, with 1 being not very empathetic, and 5 being very empathic. On average, 435 participants reported a medium likelihood of disclosing things online that they would not disclose in person $(M=2.31, S D=1.06)$. On average, 437 participants reported they visit online communities very often $(M=4.70, S D=0.78)$. Of these 437 participants, individuals indicated they felt somewhat comfortable with online communities $(M=3.53, S D=0.91)$. On average, 438 participants indicated a moderate amount of importance of online communities $(M=3.18, S D=1.20)$. Of those 437 participants who reported their level of reliance on online support, participants were not apt to rely on online support $(M=1.89, S D=0.98)$. These items represent the average response of participants on a scale of 1 to 5 .

\section{Research Design}

Participants were prompted to complete this study in three different steps (see Figure 1). Each step corresponded to one of the three purposes. In total, there were 16 experimental groups. In the first step of the study, I randomly assigned participants to one of four support-seeking post conditions. Random assignment occurred in two separate parts. First, participants received a solicitation email (Appendix A). The second step did not introduce any new experimentation. Rather, participants completed the task depending on which group they were assigned in the first step. The third step was the second experimental design, where participants were intended to be randomly assigned to one of four response conditions. Note that, as discussed below, only three conditions were used because of a technical error. 
Participants recieve solicitation email

All participants recieved informed consent and complete inital questionnaire

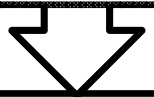

First purpose: Each participant is given 1 of 4 support-seeking post (Independent variables = level of postive-emotion words and negativeemotion words)

\begin{tabular}{|c|c|c|c|}
\hline $\begin{array}{l}\text { High positive-emotion words, } \\
\text { low negative-emotion words }\end{array}$ & $\begin{array}{l}\text { High positive-emotion words, } \\
\text { high negative-emotion words }\end{array}$ & $\begin{array}{l}\text { Low positive-emotion words, low } \\
\text { negative-emotion words }\end{array}$ & $\begin{array}{l}\text { Low positive-emotion words, } \\
\text { high negative-emotion words }\end{array}$ \\
\hline
\end{tabular}

All participants asked to complete questionnaire on pereception of distress (Dependent variable = Participant's perception of distress of poster)

Second Purpose: All participants asked to reply to recieved post (from purpose one) with their own supportive response

Participants' responses coded in LIWC (Independent variables = Level of positive-emotion words and negative-emotion words from assignment of first purpose) / Dependent variables = Level of positive-emotion words and negative-emotion words from response of second purpose)

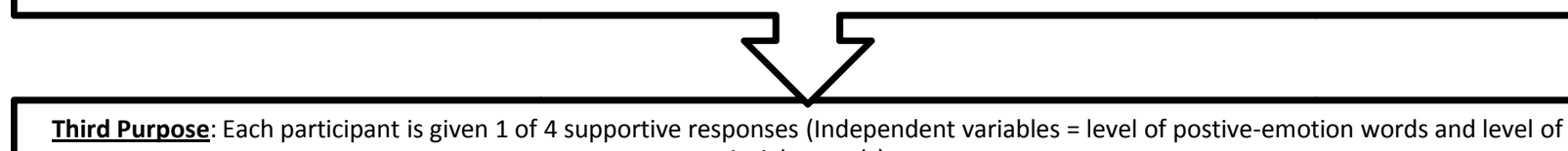

Third Purpose: Each participant is given 1 of 4 supportive responses (Independent variables = level of postive-emotion words and level of insight words)

\begin{tabular}{|c|c|c|}
\hline $\begin{array}{c}\text { High positive-emotion words, } \\
\text { high insight words }\end{array}$ & $\begin{array}{c}\text { High positive-emotion words, } \\
\text { low insight words }\end{array}$ & $\begin{array}{c}\text { Low positive-emotion words, } \\
\text { high insight words }\end{array}$ \\
\hline
\end{tabular}

All participants asked to complete questionnaire on perception of helpfulness of response (Dependent variable = Partcipant's perception of helpfulness)

Participants debriefed

Figure 1. Flow of participants in the study. This figure is an overview of the experimental process of participants of this online study. A detailed explanation of this process is overviewed in the research design section. 
To investigate the effects of language usage of an online post on perceived need for response, a 2-by-2 between-subjects design was conducted. One independent variable was level of positive-emotion words (high and low), and the other independent variable was the level of negative-emotion words (high and low). Each participant was asked to read one of four simulated online posts that contain a varied amount of positive-emotion words and negative-emotion words. The categories of high and low were defined by the differences in the percentage of words within a given category within the text analysis file. Specific definitions of high and low will be described later. For the first purpose of the study, the dependent variable was the participant's perception of distress of the poster, which was meant to measure the participant's reaction of the need to respond.

For the second purpose of the study, participants in each of the four groups were asked to provide a thoughtful response to the original post. These responses were formatted into a text analysis file and ran through the LIWC to measure the frequencies of positive-emotion words and negative-emotion words.

The third purpose of the study was to investigate the impact of varying level of positive-emotion words and insight words in simulated, supportive responses on participants' perception of the degree of effective support in response to the original post. For this second purpose I originally intended to use a second 2-by-2 between-subjects design, where each participant was assigned to one of four supportive, simulated responses that varied on the amount of positive-emotion words and insight words: (a) high positive-emotion words, high insight words, b) high positive-emotion words, low insight words, c) low positive-emotion words, high insight words, and d) low positiveemotion words, low insight words. However, due to a technical error, no participants 
were assigned to the low-insight/low-positive emotion condition. After reading the supportive response, participants were asked to complete a questionnaire that measures the level of effectiveness of the responder to make the poster feel better. Therefore, the dependent variable of the third purpose was the perceived effectiveness of support of the simulated response in reply to the original post.

\section{Independent-Variable Stimulus Materials}

\section{Simulated Post}

Simulated supportive posts were written by the author (see Appendix B). The content was designed to be similar to the posts found on sites such as Reddit. There were four simulated posts that all contained the same thematic content. I manipulated the four posts to contain either high or low amounts of positive-emotion words and negativeemotion words.

The categorical definitions (e.g., high and low) of LIWC categories (e.g., positive-emotion words, negative emotion-words, and insight words) in this study were derived from the results of research by Kahn et al. (2007). To distinguish the differences between high and low levels of LIWC categories I referred to the average LIWC categories of participants in expressive writing conditions who were instructed to write about either amusing, sad, or neutral topics. High levels of positive-emotion words were derived from the average frequency of positive-emotion words (6.24) in Kahn et al.'s amusing writing condition $(S D=3.36)$. Low levels of positive-emotion words were derived from the average frequency of positive-emotion words (1.01) in Kahn et al.'s neutral writing condition $(S D=1.08)$. In a similar respect, high levels of negativeemotion words are derived from average frequency of negative-emotion words (4.11) in 
Kahn et al.'s sad writing condition $(S D=2.28)$. Low levels of negative-emotion words are derived from the average frequency of negative-emotion words (0.27) in Kahn et al.'s neutral writing condition $(S D=0.66)$.

\section{Simulated Response}

Simulated supportive responses were written by the author (see Appendix B). The second response listed in Appendix B, low insight words and low positive-emotion words, was not used due to a researcher error. Similar to the simulated post, the response was designed to be similar to the responses found on sites such as Reddit. While the four simulated responses vary on the levels of positive-emotion words and insight words, they all contained similar content to preserve validity. Levels of positive-emotion words were derived from the frequencies of positive-emotions words previously described in the simulated post section (Kahn et al., 2007). Levels of insight words in the simulated posts are derived from the research of Pennebaker and Francis (1996). In their research, the mean results of the frequency of insight words of participants in the expressive writing condition compared to the control, or neutral, condition are referenced for this study to create appropriate levels of insight words. The simulated responses contain either high (3.3) or low (1.21) amounts of insight words.

\section{Dependent-Variable Measures}

Participants completed an initial questionnaire that covered demographics as well as background information about membership of online communities (see Appendix C). 


\section{Purpose 1: Perception of Distress}

Participants completed an online questionnaire following the experimental post. The perceived level of distress of an online post was measured using the questionnaire. The questionnaire was intended to simulate an upvote or downvote in relation to the individual's perception of whether or not the post deserves a response from the online community. While I was interested in simulating the upvote and downvote feature of Reddit, the choice to use a questionnaire with a Likert scale gave a more broad range of responses that provided more information that a yes-or-no response. The questionnaire measured the perception of distress of the individual derived from the post. This scale included 6 items designed to assess the degree to which the participants perceive the post in needing of a response. Items included a) "How willing would you be to reply to this online post with a supportive response?", b) "How important do you think it is that this post receives a reply?", c) "How much distress do you believe this individual is undergoing?", d) "How likely could this person manage without a response?” e) “To what degree do you believe this individual is wiling able to cope with his problem"? f)

"To what degree would this individual experience harm if he did not receive a response?". These itemed use a 5-point scale ranging from 1 (not at all) to 5 (completely). High scores indicated high levels of severity.

\section{Purpose 2: Linguistic Inquiry and Word Count (LIWC)}

My second purpose of this study focused on the causal role of the emotional content of language in support-seeking posts and support-seeking responses. Thus, I measured these emotional constructs by analyzing the frequency of positive-emotion words and negative-emotion words using the LIWC. 


\section{Purpose 3: Perception of Effective Support}

Participants completed an online questionnaire following the simulated response. This scale involves 6 items that assessed the level of perceived effectiveness of the response to make the author of the original post feel better. Items include a) "How effective was this response in providing emotional support to the original poster?", b) “To what degree was this response helpful in alleviating the distress of the original poster?", c) "To what degree was this response successful in making the original poster feel better?", d) "To what degree would you feel better after reading this response if you were the original poster?", e) "To what degree was this response unrelated to the original post?", f) “To what degree was this response hurtful?". These items use a 5-point scale ranging from 1 (not at all) to 5 (completely). High scores indicated high levels of effectiveness.

\section{Procedure}

Participants were recruited by an email solicitation (see Appendix A). This study was conducted as a web survey to simulate the process of an online conversation which helps to generalize the effects of this study. Participants were randomly assigned to one of the four condition groups for the first purpose through the recruitment phase. There were four possible solicitation emails, each with a link that corresponded to four different versions of the survey. Individuals were randomly assigned to one of four condition groups of the first purpose.

Participants were instructed to read the informed consent and click "next" as an indication of agreement to participate (see Appendix D). Upon completion of the informed consent form, participants were asked to complete a questionnaire for 
demographics. The questionnaire focused on demographic questions, such as gender, year in school, major, and background questions regarding membership of online communities (see Appendix C).

Then, they were presented the simulated online post. In summary, there were 12 possible groups, four possible from the first step, and each condition could be randomly assigned to three (as opposed to the originally planned four) experimental conditions of the third step. For the third step, random assignment was determined by month of birthdate. Participants were randomly assigned to one of the four conditions on the basis of the month they were born. Participants who were born in January, May, or September were assigned to the first condition; those who were born in February, March, June, July, October, or November were assigned to the second condition; and those who were born in April, August, or December were assigned to the fourth condition. Participants from the hypothetical third condition included participants who were born in March, July, or November were actually assigned to the second condition.

It is important to note that participants' exposure to the post in the first step and their supportive response during the second step may have influenced how they rated the level of effectiveness of the experimental supportive response in the third step. Having a second stage of random assignment lowered the risk of having participants influenced by their first random assignment on their perception of effectiveness in the third purpose.

For the first step, all of the four conditions were pseudo-online posts that were meant to simulate the postings of online networks that requested emotional support. To preserve validity, the online posting had the same content. Each of the four conditions 
varied based on frequency of positive-emotion words and negative-emotion words. Participants were instructed:

On the next screen, you will be presented with an emotional post that is similar to those found in an online community. Assume this post is from a stranger. You do not know the person who wrote this post. Your task is to read the online post as if you were a member of this online community. Refer to the simulated post when answering the questions.

Participants then read one of the four simulated posts. Then, participants were asked to fill out a questionnaire that measured their perception of whether or not the post deserved a supportive response (see Appendix E).

In the second step of the study, participants were prompted to respond to the original post with their natural response. Participants were prompted to write responses that filled the entire text box. The goal was to have high levels of word count in the LIWC output file so that the frequencies of affective processes were not overly saturated. In other words, longer narratives allowed for more specific analysis of the frequencies of affective processes than shorter narratives. Specifically, participants were asked:

Now we would like you to respond to the original post as if you were a member of the online community. You are free to respond however you wish but your response must fill the entire text box. This study is confidential and your answer will not be made public. You can reference the post (which is re-printed here) when writing your response.

In the third step, participants were randomly assigned to one of the four experimental response groups. Participants were instructed: 
Next, you will be asked to read a simulated reply from an anonymous Internet user to respond to the original post you just read. Your objective is to pay attention to the effectiveness of the response in meeting the emotional needs of the original post. Please answer the questions that refer to the online response. Finally, participants were given a questionnaire on the effectiveness of the supportive response (see Appendix F). Participants were debriefed (see Appendix G). Then, participants had the opportunity to enter a raffle for the gift card by entering their email in a separate link. 


\section{CHAPTER IV}

\section{ANALYSIS OF THE DATA}

\section{Content of Simulated Post and Participant Perceptions of the Poster}

For the first purpose, the association between negative-emotion words and positive-emotion words on the perception of distress was tested using a two-way analysis of variance (ANOVA) to determine if a high level of negative-emotion words and a low level of positive-emotion words predicted the perception of distress. The construct of perception of distress was measured using 6 different items on the post questionnaire. In running the two-way ANOVA on the impact of positive-emotion words and negativeemotion words on the perception of distress, I used Bonferroni adjustments, with an alpha level of .0083 , to allow for multiple dependent variables. There was no main effect found for positive-emotion words on willingness to reply, $F(1,417)=.79, p=.38, \eta^{2}=.002$. There was no main effect found for negative-emotion words, $F(1,417)=1.24, p=.27$, $\eta^{2}=.003$. There was no interaction effect found for positive-emotion words and negative-emotion words, $F(1,417)=.61, p=.44, \eta^{2}=.001$. The means of ratings of affective processes on individuals' ratings of willingness to reply with a supportive response to the emotional post are presented in Table 1. 
Table 1

Descriptive Statistics of Frequency of Positive-Emotion Words and Negative-Emotion Words of Emotional Post on Outcome Variables

\begin{tabular}{lcccccc} 
Outcome Variable & \multicolumn{2}{c}{ Low + Post } & \multicolumn{2}{c}{ High + Post } & \multicolumn{2}{c}{ Average } \\
& $M$ & $S D$ & $M$ & $S D$ & $M$ & $S D$ \\
Willingness to reply & & & & & & \\
& & & & & & \\
Low - Post & 2.34 & 1.20 & 2.57 & 1.24 & 2.46 & 1.24 \\
High - Post & 2.33 & 1.26 & 2.37 & 1.22 & 2.35 & 1.24 \\
Average & 2.33 & 1.23 & 2.47 & 1.23 & 2.40 & 1.23
\end{tabular}

Importance to receive

$\begin{array}{lllllll}\text { Low - Post } & 3.18 & 1.14 & 2.99 & 1.10 & 3.09 & 1.12 \\ \text { High - Post } & 3.35 & 1.12 & 3.35 & 0.91 & 3.35 & 1.02 \\ \text { Average } & 3.27 & 1.13 & 3.16 & 1.03 & 3.22 & 1.08\end{array}$

Emotional distress

$\begin{array}{lllllll}\text { Low - Post } & 3.60 & 0.69 & 3.23 & 0.76 & 3.41 & 0.75 \\ \text { High - Post } & 3.94 & 0.76 & 3.62 & 0.76 & 3.79 & 0.77 \\ \text { Average } & 3.77 & 0.75 & 3.41 & 0.78 & 3.60 & 0.78\end{array}$

\section{Likelihood to manage}

$\begin{array}{lllllll}\text { Low - Post } & 3.27 & 0.83 & 3.51 & 0.76 & 3.40 & 0.80 \\ \text { High - Post } & 3.07 & 0.92 & 3.27 & 0.93 & 3.16 & 0.93 \\ \text { Average } & 3.17 & 0.88 & 3.40 & 0.85 & 3.28 & 0.87\end{array}$

\section{Ability to cope}

$\begin{array}{lllllll}\text { Low - Post } & 3.09 & 0.83 & 3.46 & 0.85 & 3.28 & 0.86 \\ \text { High - Post } & 2.82 & 0.89 & 3.08 & 0.87 & 2.94 & 0.89 \\ \text { Average } & 2.95 & 0.87 & 3.28 & 0.88 & 3.11 & 0.89\end{array}$

Experience harm

$\begin{array}{lllllll}\text { Low - Post } & 2.88 & 0.98 & 2.67 & 0.87 & 2.78 & 0.93 \\ \text { High - Post } & 3.10 & 0.99 & 2.89 & 0.92 & 3.00 & 0.96 \\ \text { Average } & 3.00 & 0.99 & 2.78 & 0.90 & 2.89 & 0.95\end{array}$


Next, I examined the influence of positive-emotion words and negative-emotion words on the individual's rating of importance of the poster receiving a reply. There was no main effect found for positive-emotion words on importance of receiving a reply, $F(1$, 416) $=.83, p=.36,, \eta^{2}=.002$. There was no main effect found for negative-emotion words, $F(1,416)=6.20, p=.01,, \eta^{2}=.015$. Still, an increase in the level of negativeemotion words was associated with more importance that the poster receives a reply. There was no interaction effect found for positive-emotion words and negative-emotion words, $F(1,416)=.87, p=.35,, \eta^{2}=.002$

In regards to the association of level of positive-emotion words and negativeemotion words on level of emotional distress of the poster, there was a significant main effect for positive-emotion words, $F(1,414)=22.6, p<.0083,, \eta^{2}=.052$. In addition, there was a significant main effect for negative-emotion words, $F(1,414)=24.80, p<$ $.0083, \eta^{2}=.057$. In other words, high levels of negative-emotion words in the simulated post were associated with higher ratings of emotional distress than low levels of negativeemotion words. In addition, high levels of positive-emotion words in the simulated post were associated with lower ratings of emotional distress than low levels of positiveemotion words. There was no significant interaction between positive-emotion words and negative-emotion words, $F(1,414)=0.16, p=.69,, \eta^{2}<.000$

Next, I examined the relationship of positive-emotion words and negativeemotion words on an individual's rating of the ability of the poster to manage without a supportive response. There was no main effect for positive-emotion words on likelihood to manage, $F(1,415)=6.51, p=.01,, \eta^{2}=.016$. High levels of positive-emotion words were associated with higher ratings of likelihood to manage in comparison to posts with 
low levels of positive-emotion words. There was a main effect for negative-emotion words on likelihood to manage, $F(1,415)=7.08, p<.0083, \eta^{2}=.017$ Higher levels of negative emotion-words were associated with lower ratings of likelihood of the poster to manage without a response. There was no interaction effect between positive-emotion words and negative-emotion words on ability to manage, $F(1,415)=0.79, p=.778, \eta^{2}=$ .000 .

Next, there was a main effect for positive-emotion words on ability to cope, $F(1$, 416) $=14.17, p<.0083, \eta^{2}=.033$ High levels of positive-emotion words were associated with higher ratings of ability to cope when compared to ratings of low levels of positiveemotion words. There was a significant main effect for negative-emotion words, $F(1$, 416) $=14.69, p<.0083,, \eta^{2}=.034$. Low levels of negative-emotion words were associated with higher ratings of ability to cope when compared to ratings of high levels of negative-emotion words. There was no interaction effect between position-emotion words and negative-emotion words, $F(1,416)=0.39, p=.533, \eta^{2}=.001$.

Lastly, I was interested in the causal effects of affective processes on participants' perception of the degree to which the simulated poster would experience harm if no one had responded to the post. There was no main effect for positive-emotion words on the experience of harm, $F(1,416)=5.28, p=.02, \eta^{2}=.013$. There was no main effect for negative-emotion words on the experience of harm, $F(1,417)=5.49, p=.02, \eta^{2}=.013$. There was no interaction effect of positive-emotion words and negative-emotion words on the experience of harm, $F(1,417)=0.00, p=.99, \eta^{2}=.000$. 


\section{Content of Simulated Post and Participant-Generated Responses}

In the first purpose, participants were randomly assigned to one of four simulated posts. There were 108 participants assigned to the first group, 111 assigned to the second group, 115 assigned to the third group, and 108 assigned to the fourth group. In the second purpose, participants were asked to respond to the simulated post of the first condition. Of those that chose to respond to the simulated post condition, 73 participants responded in the first group (68\% chose to respond), 85 responded in the second group (77\% chose to respond), 76 responded in the third group (66\% chose to respond), and 76 responded in the fourth group (70\% chose to respond).

The second purpose, the association between the level of positive-emotion words and negative-emotion words of the original post and the level of positive-emotion words and negative-emotion words of the natural response, was tested using two separate twoway ANOVAs. The first two-way ANOVA determined the relationship between the level of positive-emotion and negative-emotion words of the original post on the participant's level of positive-emotion words. Similarly, the second two-way ANOVA determined the relationship between the level of positive-emotion and negative-emotion words of the original post on the participant's level of negative-emotion words. The alpha level was .025 .

First, I examined the influence of the level of positive-emotion words and negative-emotion words of the simulated post on the level of positive-emotion words in

the response. I hypothesized that the level of positive-emotion words of responses would match the level of positive-emotion words of posts because accurate empathy is a key component to providing emotional support. There was no main effect found for the level 
of negative-emotion words of the post on the level of positive-emotion words of the response, $F(1,309)=5.22, p=.023, \eta^{2}=.017$, indicating that low frequencies of negative-emotion words of simulated posts were associated with higher frequencies of positive-emotions of responses than posts with high frequencies of negative-emotion words. There was no main effect found for the level of positive-emotion words of the post on the level of positive-emotion words of the response, $F(1,309)=3.57, p=.06, \eta^{2}$ $=.012$. There was an interaction effect found for the level of positive-emotion words and negative-emotion words of the post on the level of positive-emotion words of the response, $F(1,309)=11.94, p=.001, \eta^{2}=.038$. Participants were most likely to use high frequencies of positive-emotion words when the post contained a high level of positiveemotion words and a low level of negative-emotion words. The mean outcomes of frequencies of positive-emotion words and negative-emotion words of responses as varied by levels of positive-emotion words and negative-emotion words of responses are presented in Table 2 . 
Table 2

Descriptive Statistics of Levels of Positive-Emotion Words and Negative-Emotion Words of Post on Level of Positive-Emotion Words and Negative-Emotion Words of Response

\section{Outcome Variable}

$$
\text { Low }+ \text { Post High }+ \text { Post Average }
$$

$\begin{array}{lllll}M & S D & M & S D & M\end{array}$

\section{Positive Emotion}

$\begin{array}{lllllll}\text { Low - Post } & 4.68 & 2.75 & 6.58 & 3.90 & 5.69 & 3.53 \\ \text { High - Post } & 5.10 & 2.88 & 4.55 & 2.59 & 4.83 & 2.75 \\ & & & & & & \\ \text { Average } & 4.90 & 2.82 & 5.64 & 3.50 & 5.27 & 3.20\end{array}$

Negative Emotion

$\begin{array}{lllllll}\text { Low - Post } & 2.64 & 2.52 & 2.08 & 1.56 & 2.35 & 2.08 \\ \text { High - Post } & 2.40 & 2.05 & 2.54 & 1.77 & 4.46 & 1.91 \\ & & & & & & \\ \text { Average } & 2.52 & 2.29 & 2.29 & 1.67 & 2.40 & 2.00\end{array}$

Next, I examined the influence of the level of positive-emotion words and negative-emotion words of the simulated post on the level of negative-emotion words in the response (see Table 2). There was no main effect found for negative-emotion words of the simulated post on the level of negative-emotion words in the response, $F(1,309)=$ $.21, p=.65, \eta^{2}=.001$. There was no main effect found for negative-emotion words of the simulated post on the level of positive-emotion words in the response, $F(1,309)=.88, p$ $=.35, \eta^{2}=.003$. There was no interaction effect found between positive-emotion words and negative-emotion words in the simulated post on the level of negative-emotion words, $F(1,309)=.2 .41, p=.12, \eta^{2}=.008$. 


\section{Content of Simulated Response and Participant Perceptions of the Response}

The third purpose, the association between the level of positive-emotion words and insight words of the simulated response and participant perceptions of the adequacy of the response, was originally tested using a two-way ANOVA to determine if the presence of either positive-emotion words or insight words was rated as an effective supportive response to the original, simulated post. Due to a researcher error, one condition was missing from the sample. There were four planned conditions, which varied on levels of positive-emotion words and insight words. The four conditions were intended to be (a) high positive-emotion words and high insight words, (b) low positiveemotion words and high insight words, (c) low positive-emotion words and low insight words, and (d) high positive-emotion words and low insight words. The third condition, low positive-emotion words and low insight words, was inadvertently replaced with low positive-emotion words and high insight words; therefore, there is twice the sample size for this latter condition. I accounted for this mistake by running a one-way ANOVA to determine if the levels of positive-emotion words and insight words were rated as an effective supportive response to the original poster.

In regards to whether positive-emotion words and insight words were associated with the perception of the effectiveness of the simulated response, there was a significant main effect, $F(2,342)=9.92, p<.001, \eta^{2}=.055$ (see Table 3$)$. The influence of a high level of insight words was not associated with higher scores of effectiveness; however, responses with high levels of positive-emotion words (regardless of the number of insight words) were associated with higher ratings of effective support. Next, I examined the effect of positive-emotion words and insight words on the perception of helpfulness of 
the simulated response in alleviating the emotional distress of the poster. There was a significant main effect, $F(2,342)=11.59, p<.001, \eta^{2}=.064$. High levels of positiveword words were associated with higher ratings, indicating that higher frequencies of positive-emotion words are perceived as more helpful in alleviating emotional distress. 
Table 3

Descriptive Statistics of Frequency of Positive-Emotion Words and Insight Words of Supportive Responses on Outcome Variables

\begin{tabular}{llll} 
Outcome Variable & Low Positive & \multicolumn{2}{l}{ High Positive } \\
$M$ & $S D$ & $M$ & $S D$
\end{tabular}

Effectiveness

Low Insight

High Insight

\section{Alleviated distress}

Low Insight

High Insight

\section{Successful}

Low Insight

High Insight

\section{Feeling better}

Low Insight

High Insight

\section{Related to post}

Low Insight

High Insight

$\begin{array}{llll}--- & --- & 3.42 & 0.95 \\ 2.92 & 0.98 & 3.42 & 0.96\end{array}$

3.750 .93

3.740 .92

$\begin{array}{llll}3.29 & 0.98 & 3.74 & 0.92\end{array}$

$3.42 \quad 0.96$

$\begin{array}{lcll}--- & --- & 3.51 & 0.93 \\ 2.95 & 0.96 & 3.44 & 0.93\end{array}$

Next, there was significant main effect of positive-emotion words on the level of perceived success in making the poster feel better, $F(2,342)=13.59, p=.000, \eta^{2}=.074$. A high level of positive-emotion words, as compared to a low level, resulted in higher ratings of the supportive response helping the poster feel better.

In regards to whether the level of positive-emotion words had an effect on whether the participant reported he or she would feel better if he or she was the original 
poster, there was no significant main effect, $F(2,345)=4.20, p=.016, \eta^{2}=.024$. In regards to whether the level of positive-emotion words have an effect on the relatedness of the response to the post, there was no significant main effect, $F(2,345)=5.37, p=$ $0.05, \eta^{2}=.030$. Three participants chose not to answer this item on the questionnaire. 


\section{CHAPTER V \\ SUMMARY, CONCLUSIONS, AND RECOMMENDATIONS}

The purpose of this study was to investigate the impact of language on the exchange of social support in an online community. The exchange of social support is a uniquely important area of psychology due to the prevalence of individuals who use the Internet to solicit emotional support (Skelton, 2012). These individuals in need of emotional support face potential risks of being ignored, rejected, and bullied by the Internet audience (Ries, 2010). Since many of these online communities are selfregulating websites, there is little legal and ethical oversight to protect Internet users from these potential risks. Researchers have primarily focused on naturally studying language patterns in online communication (Arguello et al., 2006; Barak \& Bloch, 2006; Davison, Pennebaker, \& Dickerson, 2000; Home \& Wiggins, 2009; Mulveen \& Hepworth, 2006; Smithson et al., 2011). However, researchers have not experimentally examined the causal effects of language on an individual's perception of a poster's level of emotional distress and a respondent's level of effective emotional support. It is imperative to understand what influence the language used in requesting and eliciting emotional support has on the Internet audience to understand if there are patterns in the way individuals react to language.

In this study, I examined the influence of language categories on the exchange of online social support, addressed in three purposes. The first purpose of this study was to 
investigate the casual effects of high and low levels of positive-emotion words and negative-emotion words within simulated posts on the perception of the poster's level of emotional distress. Second, I observed the frequencies of positive-emotion words and negative-emotion words participants used when writing a supportive response to the simulated post displayed in the first purpose. The final purpose of this study was to examine the causal effects of insight words and positive-emotion words within simulated responses on participants' perceived level of effectiveness of the simulated responder in making the poster feel better.

\section{Content of Simulated Post and Participant Perception of the Poster}

For the first purpose, I hypothesized that high levels of negative-emotion words and low levels of positive-word words would predict high levels of perceived emotional distress. I expected to find a main effect for positive-emotion words and a main effect for negative-emotion words. The comparison of means of items on the post questionnaire yielded important findings about the influence of affective processes on the perception of emotional distress.

One finding was that the level of affective processes within the simulated post had an influence on the perception of emotional distress. Ratings of emotional distress were significantly higher in conditions of high versus low levels of negative-emotion words. Low levels of positive-emotion words were associated with significantly lower ratings of emotional distress in comparison to high levels of positive-emotion words. These findings add to the literature on how others react to the frequencies of affective processes. Researchers have focused on language categories associated with health improvements (Pennebaker et al., 1997; Pennebaker \& Francis, 1996). High levels of positive-emotion 
words and moderate levels of negative-emotion words within self-disclosure narratives have been associated with health improvements over time. Researchers have theorized that positive emotions are indicative of an individual's wide range of coping skills and resiliency in comparison to individuals who report negative emotions (Fredickson, 1998). Thus, high frequencies of positive-emotion words are associated with positive physical and mental health, which may not signal to others that the individual is emotionally distressed. These findings support the literature that low levels of positive emotions are associated with higher ratings of emotional distress and high levels of negative emotions are associated with higher ratings of emotional distress.

In this study, high levels of negative-emotion words within the simulated post were associated with lower ratings of the poster being able to cope without a response. However, the level of positive-emotion words was unrelated to ratings of ability to cope. These findings provide partial support for Fredickson's (1998) theory. High levels of negative-emotion words signal limited coping signals, yet increased levels of positiveemotion words do not result in high ratings of coping skills.

Another important finding of the first purpose was a main effect for negativeemotion words on ratings of likelihood of the poster to manage without a supportive response. High levels of negative-emotion words had significantly lower ratings of likelihood to manage than low levels of negative-emotion words. Contrary to my hypothesis, there was no main effect for positive-emotion words. While the finding was not significant, there was a trend that high levels of positive-emotion words contained higher ratings of likelihood to manage. The previous finding supports the research that negative emotions are associated with limited coping resources (Fredickson, 1998). 
Overall, individuals are likely to perceive an individual as emotionally distressed, unable to cope, and unlikely to manage if the individual uses a high frequency of negative-emotion words. Before, researchers have theorized the impact of emotions on an individual's coping resources (Danner et al., 2001; Fredickson, 1998). This study adds to this literature by examining how others perceive the individual, which is important considering the context of help-seeking behavior. In requesting emotional support online, it is important to consider how others perceive individuals asking for support since most of these websites are self-regulated.

I anticipated that the responsiveness of individuals would depend on high levels of negative-emotion words and low levels of positive-emotion words. However, there were no significant effects of affective processes on participants' willingness to reply, importance that individual receive a reply, nor likelihood that the poster experience harms. These findings suggest that the emotions people use in requesting emotional support do not influence the likelihood that the Internet audience responds. This finding may be explained by the finding that affective processes were not associated with likeliness of the poster to experience harm, meaning that participants did not vary significantly in their ratings of the poster to experience emotional harm. Thus, upvotes and downvotes in online communities are not influenced by the levels of positiveemotion words and negative-emotion words that individuals use, but it does influence how other perceive their coping skills. 


\section{Content of Simulated Post and Participant-Generated Responses}

In the second purpose, when participants naturally responded to simulated posts, I found that participant's responses contained higher levels of positive-emotion words when the simulated post contained a high level of positive-emotion words and a low-level of negative emotion words. In terms of participants' levels of positive-emotion words, I expected to find a main effect for positive-emotion words and no main effect for negative-emotion words. There were neither main effects nor an interaction effect for levels of positive-emotion words and negative-emotion words on the level of negativeemotion words. These findings do not support the research that people are inclined to respond with accurate empathy (Ivey \& Ivey, 2008). I expected that individuals would match the level of positive-emotion words and negative-emotion words within their responses to empathize with the poster through the identification and reiteration of emotions used within the post. These findings suggest that individuals are likely to be positive in their supportive responses, particularly when an individual emphasizes positive emotion and uses little negative emotion (i.e., when an individual is perceived to have a high level of distress, as found in the first purpose of this study). While mental health professionals may be inclined to provide empathetic responses, it may be that laypeople when providing support are more likely to associate positivity, or positiveemotion words, as indicative of helpful support.

Furthermore, I speculate that the significant association of high level of positiveemotion words within natural responses and the post condition with a high level of positive-emotions and a low level of negative-emotion words represents a way for the responder to reinforce the poster for being positive. People may be inclined to reward a 
positive outlook, as represented by a high level of positive-emotion words and a low level of negative-emotion words, by responding in a similar positive manner. The social reinforcement of online communities in the form of "likes/dislikes" or "upvotes/downvotes" may influence responders to write a positive response. It is possible that responders are motivated to get more popularity on the online community through social reinforcement.

Since I did not find an association between high negative-emotion words of responses and high levels of negative emotion words of posts, I conclude that individuals may be intentionally or unintentionally willing to validate negative emotions. In other words, my hypothesis may be disproven because the online audience may not be willing to validate or promote negative emotions. Individuals utilizing Facebook and online health communities to lose weight reported avoiding negative people online (Newman, Lauterbach, Muson, Resnick, \& Morris, 2011). Self-disclosure on Facebook is influenced by impression management, also referred to as motivation for an individual to appear in control and positive. Therefore, this research suggests that social networking sites and online communities socialize users to present themselves in a positive manner as evidenced by positive responses from participants.

\section{Content of Simulated Response and Participant Perceptions of the Response}

For the third purpose, I expected to find a main effect for positive-emotion words and insight words on level of perceived effectiveness. Prior researchers found that supportive responses are associated with a high amount of insight words (Pennebaker et al., 1997; Schwartz \& Drotar, 2004). Within expressive writing studies, high frequencies of positive-emotion words are associated with improved physical health (Pennebaker \& 
Francis, 1996). In an observational setting, researchers found that in a bipolar chat room the word you was associated with high levels of positive-emotion words (Kramer et al., 2004). Therefore, I hypothesized that the level of positive-emotion words would be associated with perceived effectiveness.

Due to my methodological execution, I was unable to examine interaction effects. However, I did find a main effect on level of perceived effectiveness, alleviation of emotion distress, and successful in making the individual feel better. In all three of these cases, responses with a high versus low level of positive-emotion words were associated with perceptions of a more effective response, greater alleviation of emotional distress, and more success in helping the individual feel better. I did not find support for a causal effect of insight words on any dependent variables. This research suggests that individuals are sensitive to the language of emotional support. In evaluating the effectiveness of emotional support, it seems that positive-emotion words are more effective than an absence of positive-emotion words.

Theoretically, the association of positive-emotion words and high ratings of effectiveness supports one of Yalom and Leszcz's (2005) therapeutic factors, instillation of hope. Researchers have accredited positive outcomes of individuals who partake in group therapy due the perception of efficacy of treatment. While online communities do not neatly replicate group therapy, the association of effective support and positiveemotion may support the therapeutic value of hope. 


\section{Limitations of Study}

Important limitations of this study include the potential impact of the demographics of the simulated poster. These demographics may have been an unintended variable that may have influenced how participants responded. I deliberately chose to have the poster be a 20-year old, female, college student going through a break-up with a male because I believed it is a generalizable problem. However, the poster's gender, sexual orientation, and age may have played a role in participants' perceptions of emotional distress as well as the natural response they provided.

Another limitation is the demographics of the sample. Nearly three-fourths of the sample were women, so there are cautions to generalizing these findings to men. There may be gender differences in how men and women exchange online social support. In addition, the majority of participants identified themselves as Caucasian. The representations of different ethnicities were not comparable to the general population; so, it is difficult to generalize these findings to the Internet audience. Another limitation is the lack of diversity in sexual orientation. The emotional problem of this study is about a boyfriend breaking up with a girlfriend. Perhaps individuals from different sexual orientations relate to the poster in different ways. Similar to the idea of empathy, if the individual is from a different background, or in this case sexual orientation, they may have a different perspective on rating of emotional distress or how to supportively respond. In addition, the type of major and level of empathy are two variables I assessed from the initial questionnaire; however, these were not included in my analysis. Students enrolled as psychology majors and those who rated themselves as empathetic may have 
responded to the study in different ways than those enrolled in a different major or endorsed low empathy.

The simulation of an online community is another limitation of the present study. It may not have been explicit to participants that this study was a replication of an anonymous online community. Many participants responded to the simulated post as if they knew the individual personally. For example, participants referenced the website, Facebook in the content of their responses. This is a limitation because the response was intended to be an anonymous post. Facebook is an online community that links posts to a user's profile, thereby connecting the individual to the post. In this study, I was interested in individuals who anonymously post. In some responses, there was a stigma against selfdisclosing emotional posts on Facebook. Some participants criticized the poster for being so public about their emotional problems. I speculate that there are distinct differences in how people respond anonymously compared to a friend. In addition, the simulation of an "upvote" and "downvote" was used through a questionnaire. Therefore, the findings of the items on the questionnaire may not generalize to the "upvote" and "downvote" feature on an online community.

There were also methodological limitations of the current study. In the third purpose of the study, there was a condition missing from the online survey. Therefore, there were no data collected for the condition of low positive-emotion words and low insight words. In addition, the decision to have three purposes within one study resulted in possible priming effects. Participants may have experienced residual effects from the previous step of the study. For instance, the first purpose may have impacted the response of the third purpose. 
The last practical limitation is the lack of recognition of the emoji smiley face, " :) , = ), = ]" within the LIWC text dictionary. Since the LIWC text dictionary does not include the smiley face, I deleted them from text entries. The smiley face is an expression of positive emotion, so it is possible that the inclusion of the smiley face would result in higher frequencies of positive-emotion words.

\section{Suggestions for Future Research}

Future research should expand upon the limitations of this study. Researchers should focus on how demographic variables of the poster, such as gender, ethnicity, and sexual orientation, impact the perception of emotional distress. It is also important to examine how demographics of participants, like self-rating of empathy and identified major, influence the language that individuals use to respond to the poster. In addition, gender may play a factor in how individuals respond. It is possible that people of similar demographics are more likely to perceive the poster as experiencing emotional distress. It would be interesting to see if there are interaction effects between self-reports of empathy and demographic similarities between the simulated poster and participant. In the future, researchers should examine demographic variables as covariates. It is important to use different problems outlined in the support-seeking post. In this study, I chose to use a relationship break-up as a problem because I believed many people could relate to the problem. In the future, it is important to use other problems to see problem impacts the rating of emotional distress. For example, some people cited the problem as not very significant. Perhaps if the poster were to grieving the loss of a parent, or have been sexually assaulted, individuals would have rated the poster in greater emotional distress. 
Future researchers should investigate the three research questions I examined in three separate studies to isolate the findings. By designing three separate research studies, researchers would be able to eliminate confounding factors and possible priming effects. This design will would improve the confidence in the causal effects of the variables manipulated.

Another improvement for future researchers is the execution in the simulation of an online community. Researchers could use programming to create visual cues to communicate to participants that they are in an anonymous, online community. It may be important to request that the participant create an anonymous, throwaway username under which to complete the study. Another way to achieve a greater control of variables would be to examine language usage in a real online community. Future research in online communities would eliminate any confusion and unfamiliarity that participants may have experienced in this study. Future research should include observational studies to investigate the relationships among the linguistic characteristics of natural posters and those of the natural responses.

\section{Strengths of Study}

A key strength of this study was the experimental design. Prior research used the naturalistic study of language of communication in online communities (Arguello et al., 2006; Barak \& Bloch, 2006; Davison, Pennebaker, \& Dickerson, 2000; Home \& Wiggins, 2009; Mulveen \& Hepworth, 2006; Smithson et al., 2011). This study was able to determine the causal effects of language, which has created suggestions for future research. This study was therefore innovative and filled a gap in the literature of 
psychology on online communities. This design was also very streamlined because we were able to collect data for three research questions within one study.

\section{Implications}

This study has many implications for computer and telephone-mediated communication and the agencies that are providers for these services, such as suicide hotlines, online communities, and social media sites. First, mental-health care providers should provide online services for individuals with emotional distress, especially those who are suicidal. Second, these agencies should be aware of any biases in how they respond to posts or calls. It is important not to assume that individuals who do not use high frequencies of negative-emotion words are not in emotional distress or suicidal. It is possible that individuals may be masking symptoms of depression or, given the results of the second purpose, it is likely that they are rewarded to stay positive. The results of the second purpose suggested that individuals may reward high levels of positive-emotion words and low levels of negative-emotion words with positive-emotion words in the response. However, emotional distress was rated highest with positive-emotion words. So, there may be a discrepancy in that individuals recognize that support-seeking individual with negative-emotion words is less likely to cope, yet these individuals did not match the level of negative-emotion. So, individuals may learn to adopt a positive form of communication online following this operant conditioning model. 


\section{REFERENCES}

About reddit. (2012, 24 May). Retrieved from http://www.reddit.com/about/

Abbott, J., Klein, B., \& Ciechomski, L. (2008). Best practices in online therapy. Journal of Technology in Human Services, 26, 360-75. doi: 10.1080/15228830802097257

Arguello, J., Butler, B., Joyce, E., Kraut, R., Ling, K. S., \& Wang, X. (2006). Talk to me: Foundations for successful individual-group interactions in online communities. Proceedings of the SIGCHI Conference on Human Factors in Computing Systems, 959-968. doi: 10.1145/1124772.1124916

Barak, A., \& Bloch, N. (2006) Factors related to perceived helpfulness in supporting highly distressed individuals through an online support chat. Cyberpsychology \& Behavior, 9(1), 60-68. dio:10.1089/cpb.2006.9.60

Bardone-Cone, A. M., \& Cass, K. M. (2007). What does viewing a pro-anorexia website do? An experimental examination of website exposure and moderating effects. International Journal of Eating Disorders, 40(6), 537-548.

Brown , K. (Producer) (2012). The culture of reddit [Web]. Retrieved from http://www.youtube.com/watch?v=fXGs_7Yted8

Cohen, J. (1992). A power primer. Psychological bulletin, 112(1), 155.

Chung, C., \& Pennebaker, J. (2007). The psychological function of function words. Social Communication, 343-359.

Danner, D. D., Snowdon, D. A., \& Friesen, W. V. (2001). Positive emotions in early life and longevity: findings from the nun study. Journal of personality and social psychology, 80(5), 804-813.

Davison, K., Pennebaker, J., \& Dickerson, S. (2000). Who talks? The social psychology of illness support groups. American Psychologist, 55(2), 205-217.

Duggan, M., \& Brenner, J. (2013). The Demographics of Social Media Users, 2012. Pew Research Center's Internet \& American Life Project. Retrieved from http://www.pewinternet.org/2013/02/14/the-demographics-of-social-media-users$2012 /$ 
Duggan, M., \& Smith, A. (2013). 6\% of online adults are reddit users. Retrieved from http://pewinternet.org/ /media/Files/Reports/2013/PIP_reddit_usage_2013.pdf

Fox, N., Ward, K., \& O'Rourke, A. (2005). Pro-anorexia, weight-loss drugs and the internet: an 'anti-recovery' explanatory model of anorexia. Sociology of health \& illness, 27(7), 944-971. doi: 10.1111/j.1467-9566.2005.00465.x

Frattaroli, J. (2006). Experimental disclosure and its moderators: a metaanalysis. Psychological bulletin, 132(6), 823-865. doi: 10.1037/00332909.132.6.823

Gill, P. S., \& Whisnant, B. (2012). A qualitative assessment of an online support community for ovarian cancer patients. Patient related outcome measures, 3, 5158.

Greenberg, M. A., Wortman, C. B., \& Stone, A. A. (1996). Emotional expression and physical heath: Revising traumatic memories or fostering selfregulation?. Journal of personality and social psychology, 71(3), 588-602. doi:10.1037/0022-3514.71.3.588

Haker, H., Lauber, C., \& Rössler, W. (2005). Internet forums: a self-help approach for individuals with schizophrenia?. Acta Psychiatrica Scandinavica, 112(6), 474-477. doi: $10.1111 / \mathrm{j} .1600-0447.2005 .00662 . \mathrm{x}$

Hampton, K., Goulet, L. S., Rainie, L., \& Purcell, K. (2011). Social networking sites and our lives. Retrieved from: http://www.pewinternet.org/2011/06/16/socialnetworking-sites-and-our-lives/

Hardaker, C. (2010). Trolling in asynchronous computer-mediated communication: From user discussions to academic definitions. Journal of Politeness Research. Language, Behaviour, Culture, 6(2), 215-242. doi: 10.1515/JPLR.2010.011

Herring, S. C. (Ed.). (1996). Computer-mediated communication: Linguistic, social, and cross-cultural perspectives (Vol. 39). Amsterdam, Netherlands: John Benjamins publishing.

Horne, J., \& Wiggins, S. (2009). Doing being 'on the edge': managing the dilemma of being authentically suicidal in an online forum. Sociology of health \& illness, 31(2), 170-184. doi: 10.1111/j.1467-9566.2008.01130.x

Hwang, K. O., Ottenbacher, A. J., Green, A. P., Cannon-Diehl, M. R., Richardson, O., Bernstam, E. V., \& Thomas, E. J. (2010). Social support in an Internet weight loss community. International Journal of Medical Informatics, 79(1), 5-13. dio: 10.1016/j.jimedinf.2009.10.003 
Kahn, J. H., Tobin, R. M., Massey, A. E., \& Anderson, J. A. (2007). Measuring emotional expression with the Linguistic Inquiry and Word Count. The American journal of psychology, 263-286.

Khazan, O. (2010, October 25). Can reddit save lives?. Retrieved from http://www.neontommy.com/news/2010/10/can-reddit-save-lives

Kool, M. B., van Middendorp, H., Boeije, H. R., \& Geenen, R. (2009). Understanding the lack of understanding: invalidation from the perspective of the patient with fibromyalgia. Arthritis Care \& Research, 61(12), 1650-1656. doi: 10.1002/art.24922

Kramer, A. I., Fussell, S. R., \& Setlock, L. D. (2004). Text analysis as a tool for analyzing conversation in online support groups. Conference on Human Factors in Computing Systems Proceedings, 1485. doi:10.1145/985921.986096

Lepore, S. J. (1997). Expressive writing moderates the relation between intrusive thoughts and depressive symptoms. Journal of personality and social psychology, 73(5), 1030. doi: 00005205-199711000-00010

Lepore, S. J., Ragan, J. D., \& Jones, S. (2000). Talking facilitates cognitive-emotional processes of adaptation to an acute stressor. Journal of personality and social psychology, 78(3), 499-508.

Lepore, S. J., \& Smyth, J. M. (2002). The writing cure: How expressive writing promotes health and emotional well-being. American Psychological Association.

Lewis, S. P., Heath, N. L., Michal, N. J., \& Duggan, J. M. (2012). Non-suicidal selfinjury, youth, and the Internet: What mental health professionals need to know. Child Adolescemt Psychiatry Mental Health, 6(1), 13-21. doi: 10.1186/17532000-6-13.

Moreno, M. A., Jelenchick, L. A., Egan, K. G., Cox, E., Young, H., Gannon, K. E., \& Becker, T. (2011). Feeling bad on Facebook: Depression disclosures by college students on a social networking site. Depression and anxiety, 28(6), 447-455.

Newman, M. W., Lauterbach, D., Munson, S.A., Resnick, P., \& Morris, M. E. (2011). "It's not that I don't have problems, I'm just not putting them on Facebook": Challenge and opportunities in using online social networks for health. In Proceedings of the ACM 2011 conference on Computer supported cooperative work. (pp. 341-350). ACM. doi: 10.1002/da.20805

Pennebaker, J. W. (1989). Confession, inhibition, and disease. Advances in Experimental Social Psychology, 22(2), 11-244. doi:10.1016/S0065-2601(08)60309-3. 
Pennebaker, J. W. (1993). Putting stress into words: health, linguistic, and therapeutic implications. Behavior Research and Therapy, 31(6), 539-548.

Pennebaker, J. W. (2004). Theories, therapies, and taxpayers: On the complexities of the expressive writing paradigm. Clinical Psychology: Science and Practice, 11(2), $138-142$.

Pennebaker, J. W. (2011). The secret life of pronouns: What our words say about us. New York, NY: Bloomsbury Press.

Pennebaker, J. W., \& Beall, S. (1986). Confronting a traumatic event: Toward an understanding of inhibition and disease. Journal of Abnormal Psychology, 95(3), 274-281.

Pennebaker, J. W., Chung, C. K., Ireland, M., Gonzales, A., \& Booth, R. J. (2007). The development and psychometric properties of LIWC2007. Austin, TX, LIWC. Net.

Pennebaker, J. W., Kiecolt-Glaser, J. K., \& Glaser, R. (1988). Disclosure of traumas and immune function: health implications for psychotherapy. Journal of consulting and clinical psychology, 56(2), 239.

Pennebaker, J. W., Mayne, T. J., \& Francis, M. E. (1997). Linguistic predictors of adaptive bereavement. Journal of personality and social psychology, 72(4), 863.

Preece, J. (2000). Online communities: Designing usability and supporting sociability. John Wiley \& Sons, Inc.

Rainie, L., Purcell, K., \& Smith, A. (2011). The social side of the internet. Pew Internet and American Life Project.

Ridings, C. M., \& Gefen, D. (2004). Virtual community attraction: Why people hang out online. Journal of Computer-Mediated Communication, 10(1), 00. doi: 10.1111/j.1083-6101.2004.tb00229.x

Ries, B. (2010, August 31). Anatomy of an internet suicide. Retrieved from http://www.thedailybeast.com/articles/2010/08/31/reddit-suicide-how-theinternet-can-help-and-hurt.html

Rude, S., Gortner, E., \& Pennebaker, J. (2004). Language use of depressed and depression-vulnerable college students. Cognition \& Emotion, 18(8), 1121-1133.

Schwartz, L., \& Drotar, D. (2004). Effects of written emotional disclosure on caregivers of children and adolescents with chronic illness. Journal of Pediatric Psychology, 29(2), 105-118. 
Singal, J. (2012, March 7). Reddit enlists 10,000 volunteers to prevent suicides ... they hope. Retrieved from http://www.thedailybeast.com/articles/2012/03/07/redditenlists-10-000-volunteers-to-prevent-suicides-they-hope.html

Skelton, A. (2012) Social demographics: Who's using today's biggest networks. Retrieved from http://mashable.com/2012/03/09/social-media-demographics/

Smithson, J., Sharkey, S., Hewis, E., Jones, R., Emmens, T., Ford, T., \& Owens, C. (2011). Problem presentation and responses on an online forum for young people who selfharm. Discourse Studies, 13(4), 487-501.

Smithson, J., Sharkey, S., Hewis, E., Jones, R., Emmens, T., Ford, T., \& Owens, C. (2011). Problem presentation and responses on an online forum for young people who selfharm. Discourse Studies, 13(4), 487-501.

Smyth, J. M. (1998). Written emotional expression: effect sizes, outcome types, and moderating variables. Journal of consulting and clinical psychology, 66(1), 174.

Smyth, J. M., \& Pennebaker, J. W. (2008). Exploring the boundary conditions of expressive writing: In search of the right recipe. British Journal of Health Psychology, 13(1), 17. doi: $10.1348 / 135910707 X 260117$

Spera, S. P., Buhrfeind, E. D., \& Pennebaker, J. W. (1994). Expressive writing and coping with job loss. Academy of Management Journal, 37(3), 722-733. doi: $10.2307 / 256708$

Stanton, A. L., Danoff-Burg, S., Cameron, C. L., Bishop, M., Collins, C. A., Kirk, S. B., \& Twillman, R. (2000). Emotionally expressive coping predicts psychological and physical adjustment to breast cancer. Journal of consulting and clinical psychology, 68(5), 875-882. doi: 10.1037//0022-006X.68.5.875

Stanton, A. L., Danoff-Burg, S., Sworowski, L. A., Collins, C. A., Branstetter, A. D., Rodriguez-Hanley, A., \& Austenfeld, J. L. (2002). Randomized, controlled trial of written emotional expression and benefit finding in breast cancer patients. Journal of Clinical Oncology, 20(20), 4160-4168. doi: 10.1177/0261927X09351676

Tausczik, Y. R., \& Pennebaker, J. W. (2010). The psychological meaning of words: LIWC and computerized text analysis methods. Journal of Language and Social Psychology, 29(1), 24-54 doi: 10.1177/0261927X09351676.

Ullrich, P. M., \& Lutgendorf, S. K. (2002). Journaling about stressful events: Effects of cognitive processing and emotional expression. Annals of Behavioral Medicine, 24(3), 244-250.

ummmwut123. (2013, January 30). Girlfriend problem [Online forum comment]. Retrieved from http://www.reddit.com/r/MMFB/comments/17m510/girlfriend_problem/ 
Webb, M., Burns, J., \& Collin, P. (2008). Providing online support for young people with mental health difficulties: challenges and opportunities explored. Early intervention in psychiatry, 2(2), 108-113. doi: 10.1111/j.1751-7893.2008.00066.x.

Yalom, I. D., \& Leszcz, M. (2005). The theory and practice of group psychotherapy (5th ed.). New York: Basic Books.

zjbird. (2013). Make me feel better [Online forum comment]. Retrieved from http://www.reddit.com/r/mmfb 


\section{APPENDIX A}

\section{SOLICITATION EMAIL}

Dear ISU student,

I am contacting you as an invitation to participate in an exciting research study conducted for a Master's thesis in Clinical-Counseling Psychology being supervised by Dr. Jeffrey Kahn. You must be at least 18 years of age to participate in this research.

You are being contacted because you selected to be solicited for research/survey participation opportunities. You may request not to be contacted for future surveys by visiting https://helpdesk.illinoisstate.edu/ulid/ and changing your survey participation preferences. Your participation in this study is completely voluntary and to opt out of this research simply disregard this email.

This study will involve reading and responding to an online post asking for emotional support similar to what you may find on the Internet. This study is designed to be completed in no more than 15-20 minutes. Although the study may take some of your important time or lead to mild discomfort, at the end of the study you will have an opportunity to receive practical advice on emotional expression regarding negative experiences, which may improve your physical and mental health.

Also, at the conclusion of the survey you will have the opportunity to enter a raffle to win a \$25 gift card from Amazon.com. This raffle will be held on November 30, 2013, so you are encouraged to complete the survey as soon as possible.

Your input in this study will help mental health professionals understand more about online support in counseling. In addition, your input will help me to meet my degree requirements for a Master's degree in Clinical-Counseling Psychology, so you will be helping out a fellow student. 
By clicking on the link below, you will be redirected to a website for the study. There you will be prompted to provide informed consent as well as complete the survey if you choose to do so.

To participate in this survey simply click on:

https://survey.lilt.ilstu.edu/TakeSurvey.aspx?SurveyID=m13M7123

I would be delighted to respond to your questions and comments! You can email me at sabiehl@ilstu.edu.

Thank you for future time and input in this study.

Sincerely,

Ms. Sarah Biehl, Master's Student in Clinical-Counseling Psychology

Dr. Jeffrey Kahn, Professor and Thesis Chair

Department of Psychology

Illinois State University 


\section{APPENDIX B}

\section{STIMULUS MATERIALS}

Simulated posts. Words that are bolded represent positive-emotion words, whereas words that are italicized represent negative-emotion words. The post below contains a high frequency of positive-emotion words (4.71) and negative-emotion words (4.71). Therefore, this post represents a high positive-emotion words and high negative-emotion words.

Well, its midnight, meaning it's officially my $20^{\text {th }}$ birthday. Which would be great, except my boyfriend... well ex-boyfriend... just dumped me for someone else. I'm trying to stay optimistic, but I'm feeling really lost. We dated for over a year and being with him was comfortable. He goes to a different school and said it was too difficult to make it work. I feel like I'm losing the best thing that's ever happened to me. It hurts so damn much. I come off as really happy and confident when I'm around my friends, but I can't help but feel worthless right now and it makes me embarrassed that I'm even letting it get to me. It's like this freeing sense but also terrifying. All my time and energy went towards him and being alone makes me realize how empty I am. I have a couple of friends and they're there for me, but they live back home. Things will be alright eventually. I am working towards accepting that we're over. I have faith that it will get better. I hear that it gets easier as time passes but I'm about to break down and I don't 
know what to do. I keep thinking what a shitty way to start 20. Hopefully sharing this doesn't make me seem like just another emotional girl. I just wish I had someone to talk to. Please, will someone make me feel better?

The following post represents a high frequency of positive-emotion words (6.12) and a low frequency of negative-emotion words $(0.41)$.

Well, its midnight, meaning it's officially my $20^{\text {th }}$ birthday. Which would be great, except my boyfriend... well ex-boyfriend... just called it quits because he wanted to bang someone else. I'm trying to stay optimistic, and I'm feeling really positive. We dated for over a year and being with him was comfortable. He goes to a different school and said it was too much effort to make it work. I feel like I'm freed from best and worst thing that's ever happened to me. It feels so painless. I come off as really happy and confident when I'm around my friends because they're so supportive and positive when I let it get to me. It's like this freeing sense. All my time and energy went towards him and being by myself makes me realize how much I did for him. I have a couple of friends and they're there for me, but they live back home. Things will be alright eventually. I am working towards accepting that we're over. I have faith that it will get better. I hear that it gets easier as time passes but I'm keep repeating it over and over in my head and I don't know what to do. I keep thinking what a hopeful way to start 20 lol. I just wish I had someone to talk to. Please, will someone make me feel better? 
The following post contains a high level of negative emotion words (5.43) and a low level of positive-emotion words (1.45).

Well, its midnight, meaning it's officially my $20^{\text {th }}$ birthday. Which would be whatever, except my boyfriend... well ex-boyfriend... just dumped me for someone else. I'm trying not to think about it, but I'm feeling really lost. We dated for over a year and the thought of being without him is overwhelming. He goes to a different school and said it was too difficult to make it work. I feel like I'm losing him. It hurts so damn much. I come off as really put together when I'm at school and hanging out with people, but I can't help but feel worthless right now and it makes me embarrassed that I'm even letting it get to me. It's like this terrifying feeling that I'm losing him. All my time and energy went towards him and being alone makes me realize how empty I am. I have a couple of friends and they're there for me, but they live back home. I don't know how things will turn out and people tell me that I need to get over it. I'm in tears thinking what it will be like to not have him even call me on my birthday. I hear that I need to wait and let time work, but I'm about to break down and I don't know what to do. I keep thinking what a shitty way to start 20. Hopefully sharing this doesn't make me seem like just another emotional girl. I just wish I had someone to talk to. Please, will someone make me feel better?

The following post contains a low amount of positive-emotion words $(0.41)$ and a low amount of negative-emotion words (0.00).

Well, its midnight, meaning it's officially my $20^{\text {th }}$ birthday. Which would be whatever, except my boyfriend... well ex-boyfriend... just ended things with me for someone else. 
I'm trying not to think about it, but I don't know how to feel about it. We dated for over a year and the thought of being without him is something I've never had to think of. He goes to a different school and said it was too much effort to make it work. He doesn't want to see me anymore. I go back and forth about it. I come off as really put together when I'm at school and hanging out with people, but my mind has been blank since he told me. I am focusing on my homework because I have a lot of big quizzes this week. I have a couple of roommates and they're there for me. I don't know how things will turn out and people tell me that I need to get over it. It's going to be rough not hearing from him on my birthday. I hear that I need to wait and let time work, but I am finding out that I'm constantly evaluating the facts the relationship, wondering how I got here. I keep thinking what a bogus way to start 20. I just wish I had someone to talk to. Please, will someone make me feel better?

Simulated responses. The following responses were written by the author. Like the simulated post, it was designed to be similar to responses found on sites such as Reddit. Positive-emotion words are represented by words in bold and insight words are represented by words that are italicized. The first post represents the high level of positive-emotion words and high level of insight words condition.

First off, hugs. You'll get through this and come out a better person. Maybe not today, but eventually you have to realize that he's a jerk and not worth your time. You deserve someone who will make you happy. It's important to learn from this and identify any early jerk signs. Was he calling less? Not treating you right? Not saying you have to rush into another relationship, but take time to consider how he was treating you before he ended it. Also, realize that you are a worthwhile 
human being that totally deserves someone that will appreciate you. Meanwhile, I think you've acknowledged that you have problems depending on someone else and that's why you feel alone. So take time to build yourself up. College has so many built in opportunities to make friends. Have you tried joining a club? Maybe interpret this breakup as a push towards finding yourself and meeting new people. Everything will be okay. Happy birthday!

The following response represents high insight words and no positive-emotion words. This response was inadvertently left out of the study.

First off, I want to offer you my apologies, this sucks. You'll get through this and come out a different person. Maybe not today, but eventually you have to realize that he's a jerk and not worth your time. You deserve someone who will return that time and effort. It's important to learn from this and identify any early jerk signs. Was he calling less? Not treating you right? Not saying you have to rush into another relationship, but take time to consider how he was treating you before he ended it. Also, realize that you are human being that totally deserves someone that will focus on you. Meanwhile, I think you've acknowledged that you have problems depending on someone else and that's why you feel alone. So take time to build yourself up. College has so many built in activities and things to do to meet people. Have you tried joining a club? Maybe interpret this breakup as a push towards finding yourself and meeting new people. Everything sucks now but it won't soon.

The following response has no insight words and high positive-emotion words. 
First off, hugs. I want to offer you my apologies, this sucks. But hey, everything will be okay. You'll get through this and come out a better person. Maybe not today, but eventually you have to get past him being a jerk and not worth your time. You are strong though and you deserve someone who will return that time and effort. It's important to get over this from this and not make the same mistake again. Be open-minded not negative to what happened. Was he calling less? Not treating you right? Not saying you have to rush into another relationship, but take time to value yourself. Also, don't get caught up in how you appear because you are a worthwhile human being that totally deserves someone that will focus on how awesome you are. Meanwhile, I think you said that you have problems depending on someone else and that's why you feel alone. So take time to build your confidence up. College has so many opportunities to make friends. Have you tried joining a club? This breakup can be a push towards finding yourself and meeting new people. Happy birthday!

The following response has no insight words and no positive-emotion words.

First off, I want to offer you my apologies, this sucks. You'll get through this and come out a different person. Maybe not today, but eventually you have to get past him being a jerk and not worth your time. You deserve someone who will return that time and effort. It's important to get over this from this and not make the same mistake again. Was he calling less? Not treating you right? Not saying you have to rush into another relationship, but take time for yourself and give yourself time to think. Also, don't get caught up in how you appear because you are human being that totally deserves someone that will focus on you. Meanwhile, I 
think you said that you have problems depending on someone else and that's why you feel alone. So take time to build yourself up. College has so many built in activities and things to do to meet people. Have you tried joining a club? This breakup can be a push towards finding yourself and meeting new people.

Everything sucks now but it won't soon. 


\section{APPENDIX C}

\section{INITIAL QUESTIONNAIRE}

1. In what month were you born?

2. How old are you?

3. To which racial or ethnic group do you most identify?
a. Caucasian
b. African American
c. Latino or Hispanic
d. Asian/Pacific Islander
e. Native American/Inuit
f. Other, please specify

4. What is your major?

5. Please indicate your gender.
a. Woman
b. Man
c. Transgender

6. What year in college are you?
a. Freshman
b. Sophomore
c. Junior
d. Senior
e. Graduate Student

7. What is your identified sexual orientation?
a. Straight
b. Gay
c. Lesbian
d. Bisexual

8. Please rate how empathetic (the ability to understand and share the feelings of another) you are.
a. Not at all empathetic
b. Barely empathetic
c. Somewhat empathetic
d. Very empathetic
e. Extremely empathetic

9. Please rate how likely you are to disclose or share personal things online that you would not disclose in person.

a. Not at all likely to disclose

b. Barely likely to disclose 
c. Somewhat likely to disclose

d. Very likely to disclose

e. Extremely likely to disclose

10. Please rate how often you visit online communities (e.g., Facebook, Twitter, Instagram, Reddit, Pinterest, Tumblr, etc.).

a. Never visited

b. Visit once or twice in past month

c. Visit once or twice in past week

d. Visit more than once or twice in the past week

e. Visit daily

11. How comfortable are you with online communities (Internet website that connects people through series of posts and responses)?

a. Not at all comfortable

b. Barely comfortable

c. Somewhat comfortable

d. Very comfortable

e. Extremely comfortable

12. How important are online communities to you?

a. Not at all important

b. Somewhat important

c. Barely important

d. Somewhat important

e. Extremely important

13. To what degree do you rely on online support (encouragement from Internet users in response to an emotional problem)?

a. Not at all rely on online support

b. Barely rely on online support

c. Somewhat rely on online support

d. Very much rely on online support

e. Extremely rely on online support 


\title{
APPENDIX D
}

\section{INFORMED CONSENT}

\author{
Illinois State University \\ Informed Consent for Participants \\ Department of Psychology
}

Principle investigators: Ms. Sarah Biehl and Dr. Jeffrey Kahn

Please read this document carefully. Click on the link below only if you agree to participate and you fully understand your rights. Your clicking will serve as your signature, which is required for participation. You must be 18 years of age to participate in this study and to give your consent to participate in research. If you desire a copy of this consent form, you may print this page.

Thank you for taking the time to participate in this research study which is part of a Master's thesis in the Department of Psychology. The policy of the Department of Psychology is that all research participation is voluntary, refusal does not result in penalty nor loss of benefits, and you have the right to withdraw at any time, without penalty nor loss of benefits, should you object to the nature of research. You are entitled to ask questions and to receive an explanation after your participation.

Purpose of the Research

This is a research study in which we will ask you to fill out a few online questionnaires assessing your perception on an online post requesting emotional support and your perception of an online post providing emotional support. You will also be elicited to provide your own supportive response. We are interested in an evaluation of how these variables are related to one another among all study participants—we are not interested in information about any specific participants. The posts and responses used in this study are fake and are intended to mimic an online post and response.

Nature of Your Participation 
The research consists of reading a post, creating a response, and reading a response. You will be asked to complete three, short questionnaires after each step. The process is

designed to be completed in no more than 15-20 minutes. You are free not to answer questions that make you uncomfortable.

Research Procedures

In this study you will be presented with an online post, response, and brief questionnaire contained a series of questions about your perception of emotional distress and emotional support. You will be asked to provide demographic information. You will be elicited to write your own emotional supportive response.

Benefits for Participating

A benefit to you for participating is being able to learn how to write an online emotionally supportive response as well as the benefits of online expressive writing as a way to potentially improve physical and mental health. Upon completion of the survey you'll be provided with a link to a website explaining these writing exercises.

Risks and Privacy

When reading the online post and response, you may encounter thoughts and feelings that you find unpleasant, upsetting, or other objectionable. In a similar respect, when you are asked to write a supportive response you may find the process as uncomfortable. You do not have to participant if you feel uncomfortable coming up with a response.

All data will be kept secure, in accord with the standards of the University, Federal regulations, and the America Psychological Association. Since this study is completed on a computer, be sure to use a computer in which you can securely and privately complete the study. Neither names nor personally identifying information will be collected in this study.

\section{Questions or Concerns}

If you have questions about this research project, you may contact the principal investigators (Ms. Sarah Biehl at sabiehl@ilstu.edu or Dr. Jeffrey Kahn at jhkahn@ilstu.edu). If you have questions about your rights as a research participant you may contact the Research Ethnics \& Compliance Officer at (309) 438-2529 or rec@ilstu.edu

Opportunities to be Informed of Results

In all likelihood, the results will be available around May 2014. If you wish to be told the results of this research please contact Ms. Sarah Biehl at sabiehl@ilstu.edu. In addition, 
there is a chance that the results from this study will be published in a scientific psychology journal, which would be available in many libraries. In such an article, participants would be identified in general terms as students at a large state university.

Thank you again for the time and effort you are allocating to participate in this study, your participation is appreciated!

I must be 18 years of age to participate. By clicking "Next", I agree to participate in this research study. 


\section{APPENDIX E}

\section{POST QUESTIONNAIRE}

1. How willing would you be to reply to this online post with a supportive response?
a. Not at all likely to reply
b. A little likely to reply
c. Somewhat likely to reply
d. Very likely to reply
e. Extremely likely to reply

2. How important do you think it is that this post receives a reply?
a. Not at all important
b. A little important
c. Somewhat important
d. Very important
e. Extremely important

3. How distressed (suffering from anxiety, sorrow, or pain) is the person who wrote this post?
a. Not at all distressed
b. Barely distressed
c. Somewhat distressed
d. Very distressed
e. Extremely distressed

4. How likely could the person who wrote this post manage without a response?
a. Not at all likely to manage
b. Barely likely to manage
c. Somewhat likely to manage
d. Very likely to manage
e. Extremely likely to manage

5. To what degree do you believe this individual is able to cope (deal effectively with something difficult)?
a. Not at all likely to cope
b. Barely likely to cope
c. Somewhat likely to cope
d. Very likely to cope
e. Extremely likely to cope

6. To what degree would the person who wrote this post experience emotional harm if she did not receive a response?

a. Not at all likely to experience harm

b. Barely likely to experience harm 
c. Somewhat likely to experience harm

d. Very likely to experience harm

e. Extremely likely to experience harm 


\section{APPENDIX F \\ RESPONSE QUESTIONNIARE}

1. How effective was this response in providing emotional support (Internet user response to post that is intended to help the person feel better)?
a. Not at all effective
b. Barely effective
c. Somewhat effective
d. Very effective
e. Extremely effective

2. Was this response helpful in alleviating (make less severe) her emotional distress?
a. Not at all helpful in alleviating distress
b. Barely helpful in alleviating distress
c. Somewhat helpful in alleviating distress
d. Very helpful in alleviating distress
e. Extremely helpful in alleviating distress

3. Was this response successful in making the original poster feel better?
a. Not at all successful
b. Barely successful
c. Somewhat successful
d. Very successful
e. Extremely successful

4. Would you feel better after reading this response if you were the person who wrote the original post?
a. Not at all better
b. Barely better
c. Somewhat better
d. A lot better
e. Extremely better

5. Was this response related to the original post?
a. Not at all related
b. Barely related
c. Somewhat related
d. Very related
e. Extremely related 


\section{APPENDIX G}

\section{DEBRIEFING}

Responding to an emotional post can be difficult, and may lead one to feeling upset. Writing exercises can help one feel better, because they provide an opportunity to cope with negative events through the expression of emotion and gaining greater insight into the situation. Research has shown that writing about emotional topics can improve an individual's well-being. If you would like to learn about such writing experiences, please visit this website:

homepage.psy.utexas.edu/homepage/faculty/Pennebaker/home2000/WritingandHealth.ht $\mathrm{ml}$

Our research was designed to see if language influences the perception of distress in posts requesting online emotional support and the perception of helpfulness in responses providing online emotional support. We are interested if the frequencies of language influence how people respond to online support as well as what words people use when responding to an online emotional support. We believe that these questions could be very helpful for counselors in understanding how people communicate online when exchanging social support. If you'd like to learn more about this study, you can contact Ms. Sarah Biehl at her email address: $\underline{\text { sabiehl@ilstu.edu. }}$

If you are feeling distressed and would like to speak with someone, we recommend making an appointment with Student Counseling Services by calling (309) 438-3655 or stopping by room 320 of the Student Services Building (between 8:00 am and 4:30 pm Monday, Tuesday, Thursday and Friday or between 8:00 am to 8:00 pm on Wednesday) or calling the PATH hotline (available 24 hours a day) at (309) 828-1022.

Thank you for your participation! 